\title{
LAS TENSIONES POLÍTICO-ECLESIÁSTICAS EN TORNO A FERMÍN YZURDIAGA, 1936-1939*
}

\author{
POR \\ SANTIAGO MARTÍNEZ SÁNCHEZ \\ Universidad de Navarra
}

\begin{abstract}
RESUMEN: El sacerdote navarro Fermín Yzurdiaga desarrolló una notable actividad política y periodística al servicio de la Falange durante la guerra civil española. Impulsó desde Pamplona algunos proyectos culturales pioneros en la España franquista: el diario Arriba España y la revista Jerarquía. Franco le encumbró a la jefatura de prensa y propaganda de la Falange unificada, en mayo de 1937. Como clérigo, Yzurdiaga aspiró a conciliar catolicismo y falangismo. Pero sus superiores eclesiásticos le vieron con creciente recelo, por su incesante visibilidad política, por sus arengas y sermones, por sus habituales polémicas con católicos y por la incertidumbre sobre el rumbo totalitario del Estado al que Yzurdiaba servía. Su obispo Marcelino Olaechea exigió que renunciase a su protagonismo público: a la actividad política, a finales de 1937; y a la periodística, a fines de 1938. Este trabajo pretende dibujar aquel temprano choque de intereses entre los poderes civil y religioso por orientar la identidad de las iniciativas del cura azul.
\end{abstract}

PALABAS CLAVE: Fermín Yzurdiaga, Marcelino Olaechea Arriba España, Francisco Franco, Isidro Gomá, Delegación Nacional de Prensa y Propaganda de Falange Española Tradicionalista y de las Jons, Guerra Civil Española

\section{POLITICAL AND ECCLESIASTICAL STRAINS AROUND FERMÍN YZURDIAGA, 1936-1939}

\begin{abstract}
Fermín Yzurdiaga was a priest from Navarra who carried out an extremely visible political and propaganda activity for Falange, during the Spanish Civil War. Having been born in Pamplona, he carried out some pioneering cultural projects in Franco's Spain: the Arriba España newspaper and a magazine called Jerarquía. Besides, in May 1937, Franco appointed him as Falange's Press and Propaganda chief. As a clergyman, Yzurdiaga aspired to reconcile Catholicism and Falange. However, due to his constant political visibility, his speeches and sermons, his frequent controversies with many catholics, and the uncertainty about the increasingly totalitarian character of the State that Yzurdiaba was working for, he was seen by his Church superiors with increasing suspicion. The Bishop of Pamplona, Marcelino Olaechea, required him to resign both from his political activity at the end of 1937, and from his journalistic role in late 1938. Our goal is to analyze the early clashes between civil and religious authorities to control the direction of the priest's initiatives.
\end{abstract}

KEY WORDS: Fermín Yzurdiaga, Marcelino Olaechea, Arriba España, Francisco Franco, Isidro Gomá, National Delegation of Press and Propaganda of Falange Española y de las Jons, Spanish Civil War.

Recibido/Received 2011-09-23

Aceptado/Accepted 2011-11-15

- Deseo agradecer la amable ayuda y orientación de José Luis Sales Tirapu, director del Archivo Diocesano de la diócesis de Pamplona, para realizar este trabajo, realizado dentro del Proyecto de Investigación titulado "La restauración social católica en el primer franquismo, 1936-1953", HAR2011-29383-C02-02, dirigido por el catedrático José-Leonardo Ruiz Sánchez. 


\section{LETRAS Y ACCIÓN}

Fermín Izurdiaga, que nació en Pamplona el 25 de octubre de 1903, tenía nombre y abolengo navarro por los cuatro costados. Su padre Doroteo era natural de Pamplona y su madre Balbina procedía de Echarri (valle de Echauri). Sus abuelos paternos eran oriundos de Latasa y de Puente la Reina; y los maternos de Vidaurreta y Echarri. ${ }^{1}$ Andando el tiempo, Fermín cambió la ortografía de su apellido paterno, que perdió la i latina por una griega que debía de parecerle más galana. ${ }^{2}$

Ingresó en el seminario de Pamplona en 1914, donde estudió cuatro cursos de Latinidad y Humanidades (con excelentes resultados: la máxima nota, meritissimus, en las quince asignaturas) y otros tres años de Filosofía, aunque perdió el meritissimus en más de la mitad del expediente: en las materias de Lógica, Ética, Física y Griego. ${ }^{3}$

Decidió proseguir los estudios de Teología en el seminario de san Carlos de Salamanca. El chico era inteligente y tenía talento y gusto para las letras. En Salamanca existía una universidad pontificia y, allí, su carrera eclesiástica podría tener vuelos mayores. Así pues, se trasladó a Salamanca en septiembre de 1921, a punto de cumplir 18 años. ${ }^{4}$ Pero la aventura castellana sólo duró dos cursos. No es que tuviese problemas especiales de adaptación, ni dificultades con los estudios. De hecho, en el seminario le tenían bien conceptuado: el rector informará después que durante esos dos años Yzurdiaga "observó siempre muy buena conducta moral y religiosa y disciplinar, sin que obste cosa alguna que aquí se sepa, para concederle las Letras Testimoniales favorables para recibir las Órdenes Sagradas que ha solicitado".

La muerte de su padre en ese tiempo aconsejó su regreso a Pamplona, tras acabar su segundo curso en Salamanca, en junio de 1923. Él mismo nos aclara que "por motivos de salud y con autorización" del rector del seminario de Pamplona quedó como alumno externo. ${ }^{6}$ Vivía en su casa de la calle de Lindachiquia, número 4, en el casco histórico de Pamplona, junto a la parroquia de san Nicolás.

Francisco Guillén, uno de los sacerdotes de esa parroquia, también opinaba muy favorablemente sobre él. En marzo de 1924 escribió a Mateo Múgica, el obispo de la diócesis, que el joven "ha observado constantemente buena conducta moral y religiosa en conformidad con la educación cristiana que de sus padres recibiera, ha frecuentado los santos sacramentos y asistido a las funciones religiosas y enseñanza del catecismo dando señales de vocación al estado religioso". Idénticos informes positivos elevaron los curas de san Nicolás en 1925 y 1926, ${ }^{8}$ tras pedirlos el obispo. En concreto, éste quería saber:

${ }^{1}$ Archivo Diocesano de Pamplona (ADP), Expediente de Órdenes (EO), copia de la partida de bautismo de Fermín Yzurdiaga, 15-III-1924.

${ }^{2}$ Al publicar en 1927 su Poema de Navarra, su apellido se estampó por vez primera como "Yzurdiaga", aunque ya firmaba así en sus instancias al obispo de Pamplona desde 1924.

${ }^{3} \mathrm{Su}$ expediente en Humanidades y Filosofía puede seguirse por el Boletín Oficial Eclesiástico del Obispado de Pamplona (BOEOP): 15-VII-1915, pp. 231-232; 15-VII-1916, p. 243; 1-VIII-1917, p. 245; 15-VII1918, p. 219; 4-VII-1919, p. 206; 2-VII-1920, p. 195; y 15-VII-1921, p. 175.

${ }^{4}$ En Salamanca el curso académico se inauguraba el 1 de octubre (Boletín Oficial del Obispado de Salamanca, 2-XI-1921, p. 298).

${ }^{5}$ ADP, EO, informe del rector del seminario, Luis M. Albert, 17-III-1924.

${ }^{6}$ ADP, EO, solicitud de Fermín Yzurdiaga para recibir las órdenes menores, 14-III-1924.

${ }^{7}$ ADP, EO, informe de Francisco Guillén, 29-III-1924.

${ }^{8}$ Los firmó Ramón Cejalvo, coadjutor de san Nicolás, los días 4-III-1925, 23-II-1926 y 7-IX-1926. De 
"[...] si el dicho pretendiente es virtuoso, de buena vida y costumbre, pacífico, apartado de ruidos y pendencias, frecuente en los Santos sacramentos de Penitencia y Comunión, que no vive deshonestamente, ni trata con mujeres de leve opinión, ni anda de día ni de noche con hábito indecente, ni se junta con personas de mala vida, ni entra en lugares sospechosos, ni que de otra manera da escándalo con su modo de vivir, [...]". 9

Tras el visto bueno del párroco, Fermín recibió la tonsura y las órdenes menores en la primavera de 1924, el subdiaconado en 1925 y, en 1926, el diaconado (20 de marzo) y la ordenación sacerdotal (4 de octubre). Al ser el nuevo sacerdote colaborador del Diario de Navarra, este periódico recogió en su portada la noticia de su primera misa, con evidente satisfacción. ${ }^{10}$ Su primer destino -ecónomo en la parroquia de Arive, un pequeño pueblo del arciprestazgo de Roncesvalles, en los Pirineos navarros- ${ }^{11}$ fue también el último que consta sobre él en el Boletín de la diócesis. Arive era una de las casi 300 parroquias rurales de la diócesis, en la que vivían 150 vecinos. ${ }^{12}$

Además de cumplir con sus tareas pastorales en Arive, Yzurdiaga también escribió poesía. Dio a la imprenta quince poemas, que fechó en Arive en el verano de 1927, con el título Poema de Navarra. A esos versos precedía la autorización del obispo de Pamplona, Mateo Múgica, para publicar el que calificaba como "precioso trabajo". El obispo deseaba al lector los "hondos sentimientos de grandeza y de admiración" del poeta. ${ }^{13}$ Este poemario, desde luego, preanuncia la retórica grandilocuente tan habitual en sus posteriores artículos y discursos de propaganda, durante la guerra civil, estilo que Laín Entralgo denominó "estética neobarroca y neoparnasiana". ${ }^{14}$

Ni un año duró su estancia en la Montaña navarra. En diciembre de 1927 estaba de vuelta en Pamplona, para ocuparse del Hogar Escuela Infantil de la Junta de Protección de Menores de la ciudad. A eso el sacerdote añadió la fundación, en 1929, de una Casa Familia para jóvenes obreros, dependiente del Tribunal tutelar de menores. ${ }^{15}$ Es difícil precisar si Yzurdiaga maniobró para volver a la capital o si la iniciativa partió del obispo Múgica, si es que éste llamó al joven y activo sacerdote a Pamplona sabiendo inminente su nombramiento como nuevo obispo de Vitoria, publicado en enero de 1928. ${ }^{16}$ Lo cierto es que la carrera eclesiástica de Yzurdiaga no siguió el convencional y lento ritmo de ascenso desde parroquias rurales hasta otras urbanas. Al año y meses de su ordenación, Fermín se

similar redacción, eran también muy elogiosos y subrayaban que Yzurdiaga cumplía sus deberes religiosos, incluido el tiempo de vacaciones, que pasaba en Pamplona.

${ }^{9}$ ADP, EO, edicto del obispo de Pamplona, 25-II-1925.

${ }^{10}$ Diario de Navarra, 5-X-1926, portada.

${ }^{11}$ BOEOP 1-II-1927, p. 68.

${ }^{12}$ La diócesis de Pamplona tenía por entonces 1044 sacerdotes seculares, que atendían 277 filiales y 562 parroquias: 18 de término, 52 de ascenso, 196 de entrada y 296 rurales (cfr. Anuario Eclesiástico 1927: 321 Barcelona: Subirana). Sobre Arive, cfr. Anuario Eclesiástico 1923, 24 Barcelona: Subirana.

${ }^{13}$ Palabras introductorias al Poema de Navarra, Pamplona, 1927.

${ }^{14}$ Laín Entralgo, P. 1976. Descargo de conciencia (1930-1960): 188 Barcelona: Barral.

${ }^{15}$ Andrés-Gallego, J. 1997. ¿Fascismo o Estado católico? Ideología, religión y censura en la España de Franco 1937-1941: 58 Madrid: Encuentro. La Obra de los Tribunales Tutelares de Menores fue una iniciativa impulsada por los terciarios capuchinos: sobre su finalidad, trayectoria y resultados puede consultarse Roca, T. 1968. Historia de la Obra de los Tribunales Tutelares de Menores en España: 1066 pp. Madrid: Consejo Superior de Protección de Menores. Existían Casas Tutelares, Casas de Observación, Centros para Menores Anormales, y Casas de Familia: Yzurdiaga trabajó en la Casa de Familia de Pamplona, llamada Hogar de Nuestra Señora de Roncesvalles, con capacidad para 10 plazas (cfr. láminas entre las pp. 400 y 401).

${ }^{16}$ Siempre como hipótesis, en ese cambio pudo influir el sacerdote Pío Izurdiaga y Ochoa de Sagüés, administrador de la Bula de Cruzada en la diócesis y bien situado para ayudar a su sobrino. 
instaló en una Pamplona de la que ya no se movió hasta que, con la guerra civil desatada, emprendiera nuevos vuelos por otras ciudades españolas.

En la capital foral sus posibilidades de actuación se multiplicaban. En 1931, trabajaba en esas iniciativas para menores de edad y colaboraba con sus artículos para el Diario de Navarra. Además, nacida la República, fue nombrado profesor de religión en el instituto de Pamplona y consiliario de la Asociación Católica Nacional de Propagandistas. ${ }^{17}$ Fundada en 1908 por el jesuita Ángel Ayala y presidida desde los inicios por Ángel Herrera, la ACN de P pretendía formar a católicos selectos para defender a la Iglesia principalmente a través de su actividad política. La Asociación experimentó un notable crecimiento durante la dictadura de Primo de Rivera, pasando de 145 a 495 miembros entre 1924 y $1930 .^{18}$

A comienzos de 1928, en la asamblea de la Asociación en Madrid, Herrera informó de la constitución de un nuevo centro en Pamplona, que pronto tendría un presidente y un secretario, según afirmó. ${ }^{19}$ Pero pasó un año sin que el Boletín de la Asociación mencionara ni tales nombramientos, ni actividad alguna organizada por ese centro navarro. Lo más que sabemos es que, en febrero de 1929, hubo una asamblea regional de la ACN de P para Aragón, Navarra y La Rioja, a la que acudió el secretario del centro de Pamplona, Antonio Ubillos Echeverría. ${ }^{20}$ Pero en Pamplona no hay rastro de presidente o de consiliario, cargo éste nombrado por el obispo. De hecho, la capital navarra no aparece en la relación de los consiliarios de dieciocho centros de la ACN de P, publicada en su Boletín del 20 de enero de $1930 .^{21}$ En cuanto a los propagandistas navarros, lo eran José María y Ángel Huarte, José María Sagüés, Pelayo Moreno, Fermín Sanz Orrio, Antonio Ubillos y José Garrán, con quienes Ángel Herrera cenó en Pamplona el 6 de marzo de 1930, tras pronunciar una conferencia sobre la Acción Católica en la capital foral. ${ }^{22}$

Por fin, en 1930, se activó la ACN de P en Pamplona. Se debiese esto al entusiasmo de Herrera o a la incertidumbre política y social de aquel año de tránsito, el caso es que los propagandistas navarros despertaron, organizando para el curso 1930-1931 un ciclo de conferencias en torno a la encíclica de Pío XI Divini Illius Magistri, sobre la educación cristiana de la juventud. ${ }^{23}$

${ }_{17}^{17}$ Andrés-Gallego, J. 1997: 58.

18 Ordovás, J.M. 1993. Historia de la Asociación Católica Nacional de Propagandistas. De la Dictadura a la Segunda República (1923-1936): 124 Pamplona: Eunsa. Un detallado estudio sobre la ACN de P durante la época de Primo de Rivera y la II República, sin referencias a Yzurdiaga y apenas al centro de Pamplona, en Gutiérrez García, J. L. 2010. Historia de la Asociación Católica de Propagandistas. Ángel Herrera Oria. Segundo periodo (1923-1935). Madrid: CEU Ediciones.

${ }^{19}$ Boletín de la Asociación Católica Nacional de Propagandistas (BACNP), Madrid, 5-II-1928, p. 5.

${ }^{20}$ BACNP, 20-II-1929, p. 1.

${ }^{21}$ Pero se indicaba que faltaba el nombramiento de consiliario en tres centros, sin especificarlos (BACNP, 20-I-1930, p. 1). Quizá Pamplona fuera uno de ellos.

${ }_{22}$ Diario de Navarra, 7-III-1930, p. 3. De todos modos, ésta es la única vez que se habla de Sanz Orrio como propagandista. Ya era entonces abogado del Estado; en 1935, fue subjefe provincial de Falange en Navarra y jefe local de Pamplona (Sanz-Orrio y Arraiza, E. 2009. Fermín Sanz-Orrio, luchador por la justicia social: 132-133 Astorga: Akrón. Pelayo Moreno, por su parte, pasó a ser en julio de 1933 el secretario político de la recién fundada Unión Navarra, que se integró en la CEDA a finales de ese año (Ferrer Muñoz, M. 1992. Elecciones y Partidos Políticos en Navarra durante la Segunda República: 123-129 Pamplona: Gobierno de Navarra, Departamento de Educación y Cultura).

${ }^{23}$ Referencias sobre el particular, en BACNP, 20-XI-1930, p. 3; 5-I-1931, p. 4; 20-II-1931, p. 4; 5-IV1931, p. 4. Estas conferencias fueron los Círculos de Estudios para los propagandistas. La encíclica estaba fechada el 31-XII-1929. 
El estímulo para la posterior incorporación de Yzurdiaga a los propagandistas, en octubre de $1931,{ }^{24}$ debió de ser el anticlericalismo callejero y parlamentario llegado con la República. ¿Fue por iniciativa propia o por designación del obispo de Pamplona, Tomás Muñiz Pablos, que echó mano de la juventud y dinamismo de aquel sacerdote y escritor de prensa? Desde luego, Yzurdiaga debía de sintonizar entonces más con la indiferencia hacia los regímenes políticos de las iniciativas impulsadas por Herrera que con el radical antirrepublicanismo carlista o la dialéctica de las pistolas de la futura Falange. Y, por parte del obispo, fue un gesto elocuente que nombrase al primer consiliario de los propagandistas justo cuando las Cortes debatían el articulado de la nueva Constitución, que tan mal parada dejaría a la Iglesia.

Aquel otoño también ingresaron en los propagandistas algunos amigos de Yzurdiaga: José E. Uranga, Ángel María Pascual e Ignacio Ruiz de Galarreta. ${ }^{25}$ Pascual era ya el alma gemela del sacerdote -éste le introdujo como colaborador del Diario de Navarra- ${ }^{26}$ y sería luego, en la guerra civil, su principal colaborador en la puesta en marcha del diario Arriba España y de la revista Jerarquía.

El dinamismo de esta nueva hornada de propagandistas fue innegable. A partir de noviembre de 1931, analizaron la encíclica Quadragesssimo Anno (de mayo de 1931) a lo largo de catorce Círculos de Estudios. Don Fermín no quedó al margen: se encargó del tema "El trabajo. Abusos del trabajo y redención del proletariado"; redactó una ponencia sobre "La Iglesia y el Estado en los Concordatos de la postguerra"; y predicó unas conferencias cuaresmales en la parroquia de san Nicolás del 10 al 15 de febrero de 1932, sobre "Los fracasos modernos del hombre frente al problema religioso". ${ }^{27}$

Este activismo todavía perduraba en el siguiente curso, 1932-1933. Los propagandistas diseñaron un apretado programa de Círculos de Estudios en torno a la vida espiritual, la historia del cristianismo y de las religiones, y la restauración de una sociedad cristiana. Y querían consolidar o impulsar estas otras iniciativas:

"a) Continuar la publicación de la hoja quincenal "Catolicismo"; ${ }^{28}$ b) Suministrar diariamente a toda la Prensa de Pamplona una crítica solvente para las secciones de "Teatros" y "cines", como orientación moral para los lectores; c) Confeccionar un fichero de todos los pueblos de Navarra que comprenda religión, moralidad, enseñanza, periódicos, personal, política, etc., etc. d) Colaborar y trabajar con los Sindicatos profesionales y el grupo Juventud Social". ${ }^{29}$

La ambición de influir en amplios sectores de la opinión católica era patente. Al año de su renovación organizativa, la consolidación de las actividades y de los objetivos de los propagandistas navarros parecía firme. Pero aquella vitalidad fue, en realidad, aparente y caduca. Todo -personas e iniciativas- desapareció por ensalmo en el tercer curso de vida de esa renacida ACN de P local, el 3-34. La información sobre ellos que no ofrece el Boletín de la Asociación desde entonces hasta el final de la

${ }^{24}$ BACNP, 15-I-1932, p. 4, donde se aludía a la reestructuración del centro de Pamplona.

${ }^{25}$ BACNP, 15-I-1932, p. 4. Y también Florentino Carreño, antiguo secretario del centro de Oviedo afincado ahora en Pamplona. Uranga militaría después en Renovación Española, desde su constitución en Navarra en diciembre de 1935 (Ferrer Muñoz, M. 1992: 140).

${ }^{26}$ Entrevista con José Javier Uranga, Pamplona, 25-I-2011.

${ }^{27}$ BACNP, 15-I-1932, p. 4 (para las restantes actividades de ese curso, cfr. BACNP, 30-IX-1932, p. 8).

${ }^{28}$ Catolicismo. Publicación de DIARIO DE NAVARRA era una hoja volandera, de tamaño octavilla y plegada, que se repartía en las parroquias de Pamplona, con textos del Evangelio comentados por Yzurdiaga y un dibujo de Ángel María Pascual (entrevista con José Javier Uranga, Pamplona, 25-I-2011, a quien le agradezco también que me haya facilitado un ejemplar, correspondiente al "21 mayo 1933, Año I n 12").

${ }^{29}$ BACNP, 30-I-1933, p. 4. 
guerra civil, hace concluir que actividades y propagandistas se esfumaron, literalmente. No hay una sola referencia a Círculos de Estudios en Pamplona o Navarra, o a otras actividades; y, de diez propagandistas en 1933, sólo quedó en 1934 el secretario, José María Sagüés. ${ }^{30}$ ¿Qué explica este hundimiento?

Mi hipótesis es que hubo una fractura entre el secretario Sagüés y el consiliario Yzurdiaga, por divergencias en cuestiones de doctrina política. Como genuino propagandista, Sagüés querría mantener la táctica de respetar el régimen y cambiarlo desde dentro; además, la victoria de la CEDA en las elecciones de noviembre de 1933 demostraba por primera vez la validez del catolicismo político para defender a la Iglesia desde las instituciones republicanas. Pero esta victoria agudizó las tensiones entre la CEDA y el catolicismo tradicionalista, para quién el éxito cedista no era tanto un triunfo para la Iglesia como para la República, y un pretexto para forzar a los católicos a acatarla. ${ }^{31}$

El joven y emprendedor Yzurdiaga había llegado en un segundo momento a la ACN de P. Su aval entre los propagandistas era el nombramiento episcopal, pero su prestigio e influencia entre ellos también dependía de su capacidad para imprimir un nuevo ritmo a la marcha del centro navarro. Así fue. Junto con este activismo, Yzurdiaga debió de mostrar durante aquel tiempo algunas divergencias en torno a la gran cuestión del acatamiento a la República. No muy a gusto debía de estar en una Asociación católica que hacía de la acomodación a los regímenes políticos una de sus banderas de identidad.

Para el Yzurdiaga de finales de 1933, en fin, el camino para transformar España o para defender Navarra no era aceptar la República, sino la transformación revolucionaria del régimen tal como el protofascismo español venía reclamando. Así pues, para él y sus amigos propagandistas, el año 1933 debió de ser un tiempo de metamorfosis, que se cerró con su apartamiento de la ACN de $\mathrm{P}$ y de lo que ésta significaba.

Francisco Uranga Galdiano era otro de los amigos de Yzurdiaga. No militó en la ACN de P, pero sí tempranamente en Falange Española: fue el carnet número 2 por Navarra. ${ }^{32} \mathrm{Y}$, según le contó en 1937 al obispo de Pamplona, Marcelino Olaechea, Yzurdiaga no fue precisamente ajeno al nacimiento de Falange en el Viejo Reino. Así lo recordaba Uranga:

"Corría el año 1933 cuando un día de Agosto o Septiembre, me es imposible fijar día, se presentó en Pamplona el médico de Aranache, Sr. Cerdá, como delegado de las JONS de Valladolid, acompañado por D. Esteban Eanda [sic], celebrando una larga entrevista en el Diario de Navarra con D. Fermín Izurdiaga, D. Jesús Irujo, D. Pedro Uranga, el que suscribe y alguna persona más que no recuerda, tratando de fundar en Pamplona las JONS. Falange no tenía vida legal, era antes del mitin del 29 de octubre, desistiéndose de realizarla, precisamente por su carácter neutro, casi antirreligioso, influyendo en esa determinación de una manera decisiva la opinión de D. Fermín, que siempre puso por delante la necesidad de un movimiento de tipo fascista pero genuina y esencialmente Católico y Español.

\footnotetext{
${ }^{30}$ Para las cifras de miembros, ver BACNP, 15-VIII / 1-IX-1933, p. 6; y BACNP, 15-VIII / 1-IX-1934, p. 20. Para constituir un Centro hacían falta seis propagandistas; de tres a cinco para un Núcleo; y uno o dos para una Correspondencia, que es lo que pasó a ser Pamplona.

${ }^{31}$ Cfr. Moral Roncal, A. M. 2009. La cuestión religiosa en la Segunda República española. Iglesia y carlismo: 98-101 Madrid: Biblioteca Nueva; Martínez Sánchez, S. 2004. Los papeles perdidos del cardenal Segura, 1880-1957: 301-304 Pamplona: Eunsa.

${ }^{32}$ Entrevista con José Javier Uranga, Pamplona, 25-I-2011.
} 
"Posteriormente en el mes de noviembre del mismo año 1933, llegó a Pamplona nuestro Camarada Julio Ruiz de Alda con objeto de fundar Falange Española en Navarra, celebrando dos reuniones en Diario de Navarra con asistencia de D. Fermín Izurdiaga, D. Luis Ortega, D. Pedro Uranga y el que suscribe, reuniones en las que una vez aclarada entre otros extremos la confesionalidad de nuestro movimiento a satisfacción de D. Fermín se inició la constitución de la Falange de Navarra.

"A pesar de todas la seguridades recibidas de Julio Ruiz de Alda, D. Fermín, aun siendo nuestro primer orientador y rector, no formó en nuestras filas, con gran disgusto por nuestra parte, alegando su carácter sacerdotal y su deber de obediencia y sumisión a la jerarquía eclesiástica, ${ }^{33}$ y nosotros los que le hemos tratado quizá con más intimidad, podemos afirmar a su vez que no era sólo su deber, sino con más fuerza sus escrúpulos a nuestro juicio exagerados al límite". ${ }^{34}$

Como se ve, Uranga resalta el protagonismo de Yzurdiaga, lamenta sus escrúpulos a militar públicamente en Falange y enfatiza que era alguien sólo o principalmente decidido a construir un falangismo confesional. ¿Qué podía haber de malo en todo ello, a ojos del lector (el obispo)? Esta pregunta implícita recorría el texto de su informe de arriba abajo. Pero la fecha de este escrito, otoño del año 1937, su amistad con el sacerdote y el destinatario de su informe invitan a relativizar esta plácida visión sobre esa conducta exclusivamente pastoral.

Uranga quería proteger al sacerdote y a su actividad política, que eran ya vistos por sus superiores eclesiásticos con innegables recelos. ${ }^{35}$ De ahí que Uranga excluyese mencionar la incompatibilidad entre política y sacerdocio, que, más bien, a él le parecían áreas connaturales; y que, del pasado político del sacerdote, seleccionase o agrandase lo que creía que podía complacer más al lector: es decir, sus esfuerzos por catolizar Falange, un objetivo prioritario para Yzurdiaga como manifestaban estos otros hechos.

El primero tenía como protagonista al mismo José Antonio Primo de Rivera: "nuestro Gran José Antonio" accedió a que Yzurdiaga corrigiese el discurso que el fundador de Falange pronunció el 15 de agosto de 1934, al inaugurar el centro de Falange en Pamplona. Más aún, el propio Yzurdiaga "le dio el guión de asuntos a tratar exigiendo una afirmación tan clara como la de que Falange Española de las JONS “compagina esta preocupación económica [por los humildes] con la alegría y el orgullo de la grandeza histórica de España, de su sentido religioso, católico, universal". "Uranga remitía al obispo al Diario de Navarra del 16 de agosto de 1934, donde efectivamente se encuentra esa frase de Primo de Rivera en aquel acto y la noticia de que los cincuenta asistentes fueron luego a almorzar al hotel La Perla. Si Yzurdiaga se sumó a la comida y antes al acto, estaba publicitando así su alejamiento de la ACN de $\mathrm{P}$, de la que dejó de ser consiliario ese año $1934 .{ }^{37} \mathrm{Y}$, si no acudió, lo cual parece más coherente con lo que Uranga relataba, lo cierto es que ya no compartía el ideario de los propagandistas.

La información de Francisco Uranga continuaba. Aducía que las conferencias organizadas por los falangistas navarros en la primavera de 1935 eran otra prueba del empeño de Yzurdiaga por imbuir

${ }^{33}$ El obispo Muñiz había prohibido a sus sacerdotes participar en actividades políticas (Ferrer Muñoz, M. 1992: 336).

${ }^{34}$ ADP, Gobierno Diócesis (GD), informe de Francisco Uranga, 15-X-1937. Sobre la fundación de Falange en Navarra, sin mencionar ese papel de Yzurdiaga, cfr. Ferrer Muñoz, M. 1992: 142-148.

${ }^{35}$ Como demuestra esta misma petición del obispo Olaechea, que deseaba conocer los antecedentes políticos del sacerdote.

${ }_{36}$ ADP, GD, informe de Francisco Uranga, 15-X-1937. Cursivas en el original.

${ }^{37}$ Andrés-Gallego, J. 1997: 58. 
de catolicismo la Falange. El propio Uranga inauguró el ciclo, con una titulada "Falange Española, encarnación del espíritu tradicional de España". El sacerdote supervisó su texto, como si fuese un censor de los falangistas navarros, idea que Uranga deseaba resaltar al obispo:

“[...] bajo la guía de D. Fermín Izurdiaga quedó sentado con suficiente claridad la esencia de nuestro movimiento que, o se apoyaba en las esencias Católico-tradicionales de España o se disuelve en humo.

"De este modo y en todo momento D. Fermín Izurdiaga, exagerando la nota, fue nuestro censor, el que muchas veces amargaba nuestras ilusiones, viendo siempre peligros próximos o menores para España a consecuencia de una posible desviación del movimiento autoritario en un sentido absorbente que convirtiera al Estado en un dios al que se sacrificara todo, aun lo más sagrado. [...]

"En una palabra, desde que Falange nació y aún antes, desde que se sintió en España la necesidad de un Estado fuerte y totalitario, puedo afirmar que la gran preocupación de D. Fermín Izurdiaga y todos sus esfuerzos han ido encaminados a conseguir que el nuevo Estado fuera católico hasta la médula". ${ }^{38}$

Según se esforzaba Uranga en dejar claro a toda costa a su obispo, don Fermín seguía siendo en 1937 el mismo que antes de la guerra: un sacerdote-falangista libre de toda sospecha, porque adoraba a Dios y no al Estado. Explicar por qué Marcelino Olaechea no pensaba exactamente igual supone analizar el vertiginoso protagonismo y transformación del sacerdote en el primer año de la guerra civil, en el que fundó el diario ;Arriba España! y la revista cultural falangista Jerarquía. El sacerdote recibió también el premio Mariano de Cavia en 1937 por su artículo "Concilio de Santa María y Dogma de España”, aparecido en su periódico el 25 de agosto de 1936. Ascendió a la jefatura nacional de prensa y propaganda de FET de las JONS en mayo de 1937 y, en septiembre de 1937, fue invitado por Hitler al congreso en Nuremberg del partido nazi. Tanto protagonismo, inquietó a los obispos Gomá y Olaechea y a la diplomacia vaticana y causó su gradual declive y del total colapso acabando 1938.

\section{EL CAMARADA YZURDIAGA}

Marcelino Olaechea nació en 1889 en Baracaldo, en la margen izquierda de Bilbao, donde su padre era obrero siderúrgico. Ingresó muy joven en la congregación salesiana de san Juan Bosco. En agosto de 1935 fue nombrado obispo y su primera diócesis fue Pamplona, adonde llegó en noviembre de aquel año. Sus escritos y los recuerdos orales evocan su fuerte personalidad y una preocupación social a flor de piel. Lo refleja su escudo episcopal, donde una chimenea de Altos Hornos reemplazaba a los leones rampantes o las águilas: toda una declaración sobre sus orígenes y sus preocupaciones. ${ }^{39}$

Durante la guerra civil, entre éstas figuró Fermín Yzurdiaga, el más notorio de los casi mil sacerdotes seculares que tenía entonces la diócesis de Pamplona. ${ }^{40}$ A éste su fama en el Viejo Reino le

${ }^{38}$ ADP, GD, informe de Francisco Uranga, 15-X-1937.

${ }^{39}$ Sobre Olaechea, puede verse Raguer, H. 1999. "La actuación de Monseñor Marcelino Olaechea durante la Guerra Civil", en X. Quinzá Lleó y J. J. Alemany (eds.), Ciudad de los hombres, ciudad de Dios. Homenaje a Alfonso Álvarez Bolado, sj: 451-459. Madrid: Universidad Pontificia de Comillas; o Berzal de la Rosa, E. 2001. "Marcelino Olaechea Loizaga". XX Siglos 47: 83-85.

${ }^{40}$ Exactamente, 966 con él, que figuraba como "Izurdiaga Lorca, Fermín": cfr. Guía Diocesana de Pamplona, 1937: 63-82 Pamplona: Imprenta Diocesana. Sobre el clero navarro del primer tercio del siglo XX, cfr. Pazos, A. M. 1990. El clero navarro (1900-1936). Origen social, procedencia geográfica y formación sacerdotal: Pamplona: Eunsa. 
venía por su actividad periodística como colaborador del más importante y leído periódico navarro, Diario de Navarra.

En julio del 36, después de una década larga colaborando en sus páginas, el sacerdote voló de ese nido para fundar un nuevo hogar. Al empezar la guerra, Falange incautó a toda prisa el edificio, los talleres y las rotativas de La Voz de Navarra, diario nacionalista vasco aparecido en Pamplona en 1923. ${ }^{41}$ Yzurdiaga y su amigo Ángel María Pascual fueron el alma del diario que, rebautizado a partir del 1 de agosto del 36, se llamó ;Arriba España! Hoja de combate de la F.E de las JONS. Pascual fue su primer director, ${ }^{42}$ aunque era vox populi, y no pocas veces así también lo decía el propio diario, ${ }^{43}$ que lo dirigía don Fermín Yzurdiaga. La cuestión, como veremos, será fuente de graves problemas para el sacerdote.

El diario nació con admiraciones: si expresaban el fervor de la juventud, su desaparición dos meses y medio después quería mostrar la estabilidad más serena de la madurez. Y dos veces cambió el subtítulo: desde el 1 de enero del 37 tuvo el más rotundo de Primer diario de Falange Española; y, tras el decreto de Unificación de abril de 1937, quedó como Diario de Falange Española Tradicionalista y de las J.O.N.S. Para entonces, flanqueaban la mancheta los lemas "Para Dios y el César" y "España, Una, Grande, Libre".

El primer número juraba fidelidad a José Antonio. Un gran retrato suyo en portada tenía al pie este texto sin firma, aunque su grandilocuente estilo delataba al sacerdote:

"Un brazo fuerte que manda con serenidad de Jerarquía y que abraza con ardor de hermano y de camarada. Una frente, ancha y luminosa para refugio del pensamiento tradicional, que salta de los ojos en manantiales de sabiduría. Y en la maestría de la palabra caliente, exacta, combativa, la seguridad de la salvación española".

La Fuerza, la Razón y la Palabra joseantonianas guiarían la nueva España hasta derrotar a los enemigos de la Patria. Había que raer y construir, que orientar a la opinión pública con el diario, y que nutrir a las minorías rectoras falangistas con Jerarquía. Revista negra de la Falange. Fue esta revista un proyecto cultural del que sólo se editaron cuatro números, el primero en el invierno de $1936 .{ }^{44} \mathrm{De}$ hecho, el nuevo periódico anunciaba su aparición, es decir, que estaba ya pensada, ese 1 de agosto de 1936, cuando un entrefilete algo críptico decía que: "con Octubre Jerarquía". 45

La revista estaba exquisitamente editada, por el cuidado de sus editores y los espléndidos medios que la ayuda falangista podía conseguir en aquella España: "impresionaba, desde luego, el gran formato y el oro del título sobre el negro mate de la cubierta, y en el interior la calidad de los tipos, la

${ }^{41}$ Sobre estos hechos del verano del 36, sobre los miembros de su Redacción y, sobre todo, acerca del sacerdote falangista (del que hace una apasionada reivindicación), cfr. García Serrano, R. 1983. La gran esperanza. Nosotros, los falangistas: 97-99, 157 y ss. Barcelona: Planeta.

${ }^{42}$ Lo sabemos no porque el diario publicase su Redacción, sino porque el dato se escapaba entre líneas a veces, en alguna noticia. Por ejemplo: "Para Roncesvalles salieron el doctor don Daniel Arraiza, Jefe Provincial y el Dr. de nuestro periódico D. Ángel Ma Pascual, quienes cumplimentaron a nuestro amadísimo Prelado Dr. Olaechea, [...]" ( Arriba España!, 19-VIII-1936, portada).

${ }^{43}$ Por ejemplo, Arriba España, 4-II-1937, portada: a caballo entre un estilo nuevo y la obligada discreción ante el obispo Olaechea, se informaba de que "el mejor de nosotros -Ductor de esta nave de papel e ilusiones-" había recibido el premio Mariano de Cavia; 4-VII-1937, portada; etc.

${ }^{44}$ Sobre el proyecto político-cultural de Yzurdiaga, cfr. Andrés-Gallego, J. 1997: 67-130.

45 iArriba España!, 1-VIII-1936, p. 3. 
riqueza de las tintas, el negro, el rojo y el azul de las clásicas artes de imprimir, la profusión de culs-delampe y adornos adicionales", cuenta Laín Entralgo, uno de sus colaboradores. ${ }^{46}$

El primer equipo de Redacción, "Escvadra" fue llamado, lo formaban Yzurdiaga como Jefe, y diez más: Carlos Foyaca de la Concha, Rafael García Serrano, Alfonso García Valdecasas, Ernesto Giménez Caballero, Pedro Laín Entralgo, Eugenio Montes, Crispín Martínez (ilustrador), Ángel María Pascual Viscor (editor), José María Pérez Salazar y Víctor de la Serna. Su primer número incluyó también versos de Joaquín Arbeloa y Manuel Iribarren, y colaboraciones de Eugenio d'Ors, Francisco Uranga y Fermín Sanz Orrio. De este plantel de extraordinario talento literario sólo perduraron el director y editor. Nuevos colaboradores se unieron en el número segundo (octubre de 1937): Paul Henri Michel, Gonzalo Torrente Ballester, Basterra, Agustín de Foxá, Luis Rosales, Eladio Esparza (subdirector de Diario de Navarra), Dionisio Ridruejo, Juan Pablo Marco (seudónimo de Juan José López Ibor) y Manuel Ballesteros. En el tercero (marzo de 1938) aparecieron colaboraciones de José María Pemán, fray Justo Pérez de Urbel, Luis Legaz y Lacambra, Adriano del Valle, Luis Felipe Vivanco, Pascual Galindo, Daniel de Aramio y Carlos Ribera. Y para el último número (del que sólo se dio el año, 1938) escribieron Bruno Ibeas, Joaquín de Entrambasaguas, Augusto Andrés Ortega, Manuel Díez Crespo, Armando Lodolini, Teófilo Ortega y Ángel B. Sanz. Arriba España se nutrió de artículos de d'Ors, Torrente Balleter, Laín Entralgo, Pérez de Urbel o Giménez Caballero, entre otros. El ambicioso proyecto de renovación política y cultural de Yzurdiaga se completaba con "Jerarquía. Ediciones de las dos espadas".

Empezada la guerra, el sacerdote tenía algunos ejes claros: la guía joseantoniana, una trinidad de empresas político-culturales y los enemigos que batir. La primera portada del recién nacido ;Arriba España! enmarcaba una declaración de principios, que reclamaba hogueras. Bajo el punto de vista de Yzurdiaga y sus colegas, el fuego iluminaba y despejaba por igual la labor doctrinaria que el diario falangista acababa de iniciar:

“;Camarada! Tienes obligación de perseguir al judaísmo, a la masonería, al marxismo y al separatismo. Destruye y quema sus periódicos, sus libros, sus revistas, sus propagandas. ¡Camarada! Por Dios y por la Patria”.

Los enemigos no cambiaron durante la guerra. Sí varió la intensidad de las críticas del diario hacia unos u otros. A todos ellos iArriba España! pronto unció la crítica a las viejas argucias de los liberales, que habían llevado a España al precipicio, según se afirmaba. ${ }^{47}$ Sin duda, los más combatidos fueron los católicos populistas o sturzistas, ${ }^{48}$ atacados con una inquina constante.

${ }^{46}$ Laín Entralgo, P. 1976: 210-211. A Dionisio Ridruejo (1977. Casi unas memorias: 118 Barcelona: Planeta) todo aquel esmero le parecía "poco combatiente". Un reciente trabajo analiza los contenidos y vinculación entre Jerarquía y su homónima italiana Gerarchia: Sesma, N. 2011. "De la elite intelectual a la aristocracia política. El discurso de la renovación ideológica y generacional en Gerarchia. Rassegba mensile della rivoluzione fascista y Jerarquía. La revista negra de la Falange", en Francisco Morente (ed.), España en la crisis europea de entreguerras. República, fascismo y guerra civil: 269-288. Madrid: Libros de la catarata. La revista, por otra parte, puede consultarse en su reciente edición: Jerarqvía. La revista negra de la Falange (19361938). Edición íntegra. Introducción de José Luis Orella Martínez. 2011. Madrid: Ediciones Barbarroja.

${ }^{47} \mathrm{La}$ andanada comenzó con el editorial "Cruzada contra la Política", en la portada del 6 de agosto de 1936, redactado por el "Jefe de Propaganda" de la Falange navarra, el propio Yzurdiaga.

${ }^{48}$ El sacerdote Luigi Sturzo, fundador del Partito Popolare Italiano, estaba en el exilio desde 1924 y su partido fue suspendido en 1926. La alusión a los "populistas" se refiere al principal partido integrado en la CEDA: Acción Nacional (luego Acción Popular), creado por Ángel Herrera en 1931. 
En cuanto al César, la guía de José Antonio, el Ausente, la reemplazó primero Manuel Hedilla ${ }^{49}$ y luego, a partir de abril de 1937, Francisco Franco. La inspiración procedía de Primo de Rivera y de sus poco orgánicos postulados. Pero la obediencia fue para Franco, el Caudillo a quien Yzurdiaga se sometió gustoso y cuyo protagonismo se incrementó en el Arriba España desde el decreto de unificación política de abril de 1937.

Y en cuanto a Dios, la guerra acentuó los esfuerzos de Yzurdiaga y de su diario por hacer compatibles catolicismo y falangismo. $\mathrm{Y}$ por combatir a quienes dudaban o criticaban aquel nuevo dogma de fe que definía a Falange, en frase muy querida del sacerdote, como "Milicia de Dios, Milicia del Imperio". ${ }^{50}$ Con el celo del converso, en su artículo "Falange Española e Iglesia Católica", aparecido en la portada del 11 de septiembre de 1936, Yzurdiaga juró odio cartaginés contra los católicos acomodaticios, los populistas de la ACN de P:

"La Jefatura Territorial de Prensa y Propaganda ha publicado en ¡Arriba España! varios magistrales artículos sobre la posición de Falange Española y la Religión y la Iglesia Católica. Porque la cobardía, aliada con la más supina ignorancia de nuestro Credo, nos quiere presentar como un movimiento irreligioso y ateo.

"La Masonería que ya ha perdido en España una privilegiada trinchera, quiere enroscarse solapadamente en el Movimiento Salvador de la Patria, ella dejó correr la calumnia contra nuestra gloriosa Falange. Y la Falange estará implacable contra los enemigos de España. Somos Católicos, sencillamente. Nacidos en la persecución nos asemejamos a los primeros cristianos perseguidos en las Catacumbas; como ellos, auténticos, evangélicos, ecuménicos, católicos.

"iQue nos oigan todos!

"Y si aun hay católicos de marca "populista" blandos, adulterados, mercaderes del Evangelio, que quieran con sus mentiras desviar el destino Misionero de la Falange, que teman al Cristo sublime que en los atrios del Templo restalló sus látigos contra los vendedores y profanadores de su Palabra. Después, que teman también a la Falange. [...]”.

Esta insistencia sobre la Falange católica fue un eje propagandístico de su actividad. Así lo enfatizaría luego Uranga en su escrito al obispo. Con todo, Marcelino Olaechea pudo percibir desde el principio que la católica visión de Yzurdiaga era, más bien, poco universal y más bien excluyente: partía y separaba más que unía y pacificaba.

Poco ayudaban la contundente vehemencia de éste y otros artículos suyos de prensa o sus discursos sobre las relaciones entre Falange y fe católica, que revelaban un temperamento agresivo y polemizante. El sentimiento de agravio, la exigencia de disculpas, las amenazas retóricas hacia los enemigos de una Falange ingenua y caballerosa eran un crescendo habitual en el argumentario de Yzurdiaga. Se hacía portavoz ante los católicos y falangistas españoles de un proyecto conciliador, tal como él lo entendía, que no iba a gustar en absoluto a los primeros y que no encajó demasiado bien entre los segundos.

49 "Los de Arriba España éramos hedillistas hasta las cachas" (García Serrano, R. 1983: 228).

50 ¡Arriba España!, 16-VIII-1936, portada. La primera muestra de esta Falange católica fue un manifiesto publicado en ;Arriba España! el 18 de agosto, exigiendo a la Diputación restaurar la Compañía de Jesús, "milicia de Cristo y de España". Entregaron el manifiesto a Olaechea y a Gomá, que agradecieron la iniciativa (;Arriba España!, 19-VIII-1936, portada). En realidad, La Diputación ya había tomado la decisión de restablecer a los jesuitas el 15 de agosto, lo que hizo público el día 19, cuando Arriba España pretendía capitalizar una medida en la que su protagonismo fue improvisado, como poco (Del Burgo, J. 1970. Conspiración y guerra civil: 42-43 Madrid-Barcelona: Alfaguara). 
Esta beligerancia de Yzurdiaga de la que hemos visto un primer botón de muestra, le trajo de sus superiores eclesiásticos muchos quebraderos de cabeza. El sacerdote y su diario criticaban las posiciones divergentes de los otros diarios navarros, el carlista El Pensamiento Navarro y el conservador Diario de Navarra. Disentir era una obligación del oficio periodístico y una consecuencia de la disparidad ideológica de las tres publicaciones. Pero estas discordias desgastaban la sotana que le revestía. Eso y las polémicas locales en las que el diario censuraba iniciativas diocesanas le gustaban muy poco al obispo Olaechea.

Los roces entre el Arriba España y el obispo tardaron en producirse. Es difícil saber si Marcelino Olaechea apreciaba o no al diario y a su línea editorial. Pero, cuando la criatura aún no había cumplido su primer año, el obispo protestó por un artículo del 17 de junio de 1937 que cuestionaba una campaña de moralidad de la Acción Católica, que Arriba España bautizó socarronamente como "la lucha a muerte contra la frivolidad". "Al día siguiente, en una carta privada al director del periódico, el obispo le afeó las "alusiones desagradables" contra una campaña que se había "sujetado a mi estudio y decisión, hasta los detalles", pero de sus palabras finales no parecía desprenderse ninguna tirantez particular:

"Agradezco a V. y a todos esos buenos amigos de ARRIBA ESPAÑA el cariño que me tienen y el decidido apoyo, que como buenos hijos de la Iglesia, vienen prestando a mi actuación. De todo corazón y como gran amigo ruego al Señor les bendiga largamente". ${ }^{52}$

Unos días más tarde, el 22 de junio, la contraportada del diario titulaba: "El Sr. obispo de Pamplona bendice a Arriba España". El diario transcribía y glosaba el párrafo anterior:

"Con este motivo reiteramos una vez más nuestra adhesión de siempre, -hasta el sacrificio de la sangre y de la vida- a la fe de Jesucristo, a la autoridad y jerarquía de la Iglesia romana, y exigimos que el nombre de "Arriba España" -porque lleva también encima el nombre de Dios, "Para Dios y el César" reza nuestra cabecera- no sea tirado como lo manda Jesucristo en aquel símbolo ameno de las margaritas, a los puercos y a las bestias".

\section{UN CURA EN EL CANDELERO}

Tanto la intervención del obispo como la recargada contestación, del estilo de Yzurdiaga, se entienden mejor en su contexto. El cura acababa de ser nombrado en mayo Delegado Nacional de Prensa y Propaganda de la Falange unificada por Franco el 19 de abril. Se trataba de una estructura falangista, paralela a otra Delegación Nacional de Prensa y Propaganda, creada en enero de ese mismo año. ${ }^{53} \mathrm{El}$ caso es que don Marcelino se enteró de aquel encargo por la prensa y le expresó al sacerdote su desagrado el 8 de mayo de 1937:

"Muy querido don Fermín:

"Juzgue, por el gran aprecio en que le tengo, la pena que siento al no poderle felicitar, por el honroso encargo que se le ha confiado con el nombramiento de Delegado Nacional de Prensa

${ }^{51}$ Arriba España, 17-VI-1937, p. 2.

${ }^{52}$ ADP, GD, Olaechea al director de Arriba España, 18-VI-1937.

${ }^{53}$ Sinova, J. 2006. La censura de prensa durante el franquismo: 96-99 Barcelona: Debolsillo. Para una visión panorámica sobre la organización de la prensa y la propaganda en la España franquista durante la guerra civil, cfr. Domínguez Arribas, J. 2009. El enemigo judeo-masónico en la propaganda franquista (1936-1945): 162-175 Madrid: Marcial Pons Historia. 
y Propaganda del Movimiento de Falange Española Tradicionalista de las Jons, pues como no recuerdo que me haya hablado de este asunto, me ha sorprendido ver su nombramiento en la prensa.

"No sé el alcance del mismo ni a qué ausencias de la Diócesis le ha de obligar; y así le ruego me lo haga presente, en cuanto V. lo sepa, para que veamos de dejar a salvo lo que disponen las leyes de la Iglesia, en particular los CC. 1386 y 143. Ello será para V. y para mí un consuelo y la seguridad de acierto". ${ }^{54}$

Esos cánones del Código de derecho canónico prohibían al clero secular publicar o dirigir diarios y revistas y ausentarse de la diócesis, sin permiso del obispo. Lo segundo parecía ahora muy posible con ese nuevo cargo de ámbito nacional: aunque sus viajes fuera de Navarra no iban a estorbar las tareas pastorales de Yzurdiaga, por la sencilla razón de que no las tenía. Y lo primero lo venía haciendo Yzurdiaga desde el año anterior en Arriba España y en Jerarquia. ${ }^{55}$ De hecho, sus colaboraciones y orientaciones periodísticas eran bien conocidas, y permitidas, por su obispo, al que ahora le preocupaban las complicaciones derivadas de sus nuevos vuelos políticos. De ahí que don Marcelino le recordase que necesitaba su visto bueno episcopal: y parecía dispuesto a dárselo, más que a negárselo. Ambos se vieron y el sacerdote quedó en decir a Franco que le pidiesen al obispo su venia: "petición que le prometen a él, según me asegura, y a cuyo examen condicionaré mi plácet", le decía más tarde Olaechea al obispo de Gerona, Mons. Cartañá. ${ }^{56}$

Dos meses después, Marcelino Olaechea andaba escamado porque nadie le había pedido el plácet. Aunque tampoco él lo había exigido, o prohibido a Yzurdiaga ejercer como Delegado de Prensa y Propaganda hasta que solicitaran su venia. En cualquier caso, no olvidó recordarle al sacerdote que le debía una promesa cuando le volvió a escribir el 5 de julio del 37:

"Sé por la prensa que tiene V. mañana en Valladolid" ${ }^{57}$, una conferencia que será radiada. Creo que esta conferencia es una exigencia de su cargo; sobre el que espero aquella petición (de la que hablamos) por parte de nuestras Autoridades; petición que me dejará a mi con el consuelo de haber cumplido con mi deber.

"Pido a Dios que le asista con su divina gracia, para que sus palabras hagan mucho bien.

"Estoy cierto de que las dirá V. como sacerdote, como buen sacerdote que es; y con su sotana, que sabe V. honrar.

"Le digo esto último, porque me dicen que en Bilbao le veían sin ella. Fuera de los capellanes del frente, ninguno puede dejar de llevarla, como V. sabe; y hará con ella mayor bien". 58

El sacerdote le respondió inmediatamente, "cuando las amarguras de todo orden me cercan despiadadamente: me siento batido de todas partes". ${ }^{59}$ Le confirmó "que me aconsejaron hablara

${ }^{54}$ ADP, GD, Olaechea a Yzurdiaga, 8-V-1937.

55 Eso sí, sin que el diario publicitara el hecho salvo raramente: por ejemplo, la portada de Arriba España del 11-VII-1937 aclaraba que Fermín Yzurdiaga era «Director de ARRIBA ESPAÑA y de JERARQVÍA». Olaechea tardó bastante tiempo en poner ese cascabel al gato.

56 ADP, GD, Olaechea a Cartañá, sin fecha. Cartañá estaba desplazado de su diócesis y residía en Pamplona

${ }^{57}$ En realidad, fue en Zaragoza y el 10 de julio de 1937.

${ }^{58}$ ADP, GD, Olaechea a Yzurdiaga, 5-VII-1937; cursivas en el original.

${ }^{59}$ En esos frentes se incluía también la Delegación del Estado para Prensa y Propaganda -Yzurdiaga dirigía la paralela de Fet de las Jons-, cuyo Jefe acababa de telegrafiar al director del Arriba España ese mismo 5 de julio del 37: "SIENTO COMUNICARLE QUE SI VUELVEN A INFRINGIR LAS ÓRDENES DE ESTA 
vistiendo el uniforme y así iba a hacerlo. Contadas veces lo he vestido, pero siempre con aquella honestidad de sentirme un sacerdote-soldado". Además, le recordaba sus razones para embarcarse en esas aventuras políticas:

"Muchas veces le he confesado, con la verdad y lealtad de mi temperamento, lo que me trajo a estas actuaciones públicas. Creí encontrar no sólo con las aprobaciones frías sino con el calor de toda mi Jerarquía [eclesiástica], en un negocio en el que tanto le va a nuestra inmortal Iglesia Española. Mañana martes [6 de julio] salgo para Salamanca. Quiero tratar con el Generalísimo despacio de todos estos asuntos. Llevo la intención de suplicarle me aparte, por lo que más quiera, de todas estas actividades, para volver a la paz y a la grandeza de los apostolados obscuros, donde no haga sombra a nadie, sino es a mí mismo. Pero vea, mi queridísimo Sr. Obispo -y se lo digo sin asomo de queja, sino en la confianza del cariño- que durante la República algunos sacerdotes se movían en la más turbia política y hasta alguno de la minoría vasca llegó al sumo sacerdocio del pontificado. ${ }^{60} \mathrm{Y}$ ésta, es otra hora bien distinta en misión y en grandeza. A mi vuelta de Salamanca le visitaré, para tener, siquiera el consuelo de su palabra y de su bendición. Que algún día no se lamente que fui necesario y no me dejaron trabajar". 61

Yzurdiaga pronunció su conferencia en el Círculo Mercantil de Zaragoza el sábado 10 de julio: el Arriba España la reprodujo el día siguiente en portada, a toda página. Se ve que Franco le disuadió de dimitir de su cargo, si es que hablaron de tal asunto, y que don Marcelino aceptó sus razones, aunque subrayándole por escrito, el mismo 6 de julio, que andaban en juego intereses más importantes que los políticos, que eran los que tan firmemente sentía Yzurdiaga:

"Muy querido Don Fermín, le agradezco su carta, tan sincera. En esta prueba de desamparo y en las mayores que tendrá por la soledad en que le dejan, me tiene y me tendrá consigo. Ya verá, con la gracia de Dios, que sé tener algo más que aportaciones frías.

"Ese deber y ese placer de estar con V., querido Don Fermín, es el que me mueve a decirle las cosas que le digo, para su mayor acierto y consuelo en ese cargo y en los que le vengan.

"Celebro que venga a verme.

"Vivimos días transcendentales. Las transigencias de ahora, las confusiones de ahora y las ignorancias que se tienen ahora de los derechos de la Iglesia, pueden enturbiar por mucho tiempo la clara corriente de nuestro glorioso movimiento.

"Los que estamos en alto (y Dios le ha puesto a V. muy en el candelero) tenemos deberes rigidísimos.

"Yo no sé del caso concreto a que V. alude [el de Pildain]; y aún me animo a pensar que si la Santa Sede lo eligió ad regendam Ecclesiam Dei, no sería partidista; pero en tesis, tiene V. razón. Yo lo repruebo con toda mi alma; y tuve y tengo para todos los sacerdotes las mismas palabras: "sacerdotes, y nada más sacerdotes"; "padres de todos - lazos de unión de todos". "Almas; almas que lo demás nos sobra".

DELEGACIÓN ESPECIALMENTE LA REITERADA DE NO INDICAR EL ORIGEN DE LAS CIRCULARES SERÁ SANCIONADO ESE DIARIO STOP ÚLTIMA INFRACCIÓN COMETIDA EN EL NUMERO DEL TRES DE JULIO" (Archivo General de la Administración, Cultura, caja 21/1357). Se refería a una "Circular de Salamanca" que, publicada en las páginas 3 y 4 del 3 de julio, parecía un argumentario contra el separatismo vasco, del que se cantaba su fin.

${ }^{60}$ Se refería a Antonio Pildain, consagrado obispo de Canarias el 14 de febrero de 1937, en Roma.

${ }^{61}$ ADP, GD, Yzurdiaga a Olaechea, sin fecha [5-VII-1937]. 
"El traje talar es nuestro distintivo y nuestra gloria; y en la nueva España es ocasión venturosa para que las gentes alaben a Dios.

"De alguno he sabido yo que, como V. dice, vestía uniforme de requeté en solaz de cafés y recreos. No he dejado de llamarlo al orden, y a uno de retirarlo de campaña. Ya ve que me hago cargo. Ya charlaremos. Un abrazo". ${ }^{2}$

Estas cartas revelan matices sobre el mismo tono. Yzurdiaga afirmaba en público y en privado que su misión era armonizar catolicismo y Falange, y que se le incomprendía y perseguía. Su obispo le alentaba, consolaba y recordaba sutilmente que su buena voluntad no era tan decisiva como él creía. El punto de discordia era la cuestión, sólo en apariencia una cuestión formal, de la independencia franquista ante la autoridad eclesiástica al no solicitar un permiso que, da toda la impresión, Olaechea habría concedido en aquel inicio del verano del 37. Pero, sin ninguna duda, no más tarde, por el crescendo de hechos que desgastaron al cura azul fuera del mundo falangista.

\section{EL DESGASTE DE LA SOTANA AZUL}

A comienzos de agosto de 1937, Arriba España lanzó una campaña para que la Diputación foral presupuestase una partida para aumentar los salarios del clero rural navarro. El Pensamiento Navarro atribuyó intenciones torcidas a su campaña y el 17 de agosto el diario falangista criticó con dureza al rotativo carlista. Además, como la Diputación no rectificaba, el 20 de agosto Arriba España informó en portada que esa insensibilidad era lamentable tras veinte días de campaña tenaz y que era generoso quien tenía veinte céntimos y daba diez, y no quien tenía un millón y daba dos pesetas.

El Gobernador civil de Navarra, Francisco de la Rocha, pensó que se habían pasado de la raya y, el 21 de agosto, informó al obispo sobre "cierta aptitud [sic]" tomada por Yzurdiaga - ¿la escalada de sus críticas?- y para agradecerle "la amabilidad y atención [con] que ha acojido [sic] mis consultas y las facilidades que me ha prestado". ${ }^{63}$ Aunque fue poco explícito, De la Rocha debió de prohibir la campaña, porque en adelante Arriba España olvidó su cruzada en pro del clero navarro.

Dos semanas después, el obispo Olaechea escribió de nuevo al sacerdote. Había leído en el Arriba España del día anterior, 3 de septiembre, que Hitler le había invitado al congreso del partido nacionalsocialista en Nuremberg (del 7 al 11 de septiembre), como "“"Huésped de honor" de Alemania", y la ambigua respuesta que recogía igualmente la noticia: "Nuestro Jefe Nacional de Prensa y Propaganda ha correspondido cordialmente a esta alta y honrosa distinción del Caudillo Alemán, prometiendo su asistencia, si se lo permiten los muchos trabajos de su Delegación". ${ }^{4}$

En su carta, Olaechea le indicaba que "en las palabras 'prometiendo su asistencia si se lo permiten los muchos trabajos de su Delegación', creo que se esboza una buena excusa para no asistir,

${ }^{62}$ ADP, GD, Olaechea a Yzurdiaga, 6-VII-1937. La respuesta del sacerdote fue muy elocuente: "Estos actos me resienten mucho la salud, pero no veo otro medio para salvar este momento que es, créamelo, dificilísimo. Yo al menos tengo miedo de la confusión ambiental en todos los órdenes. Me dicen que tengo una gran responsabilidad y que acaso posea la solución. Pues yo lucharé hasta el fin. Y más ahora con el afecto de V.E." (ADP, GD, Yzurdiaga a Olaechea, sin fecha).

${ }^{63}$ ADP, GD, De la Rocha a Olaechea, 21-VIII-1937.

64 Arriba España, 3-IX-1937, portada. Desde 1933, al Congreso nazi de Nuremberg acudían diplomáticos y periodistas extranjeros invitados. En 1937 fueron, por vez primera, los embajadores de Inglaterra y Francia, no así el nuncio Cesare Orsenigo (cfr. d'Almeida, F. 2008. El pecado de los dioses. La alta sociedad y el nazismo: 267-274 Madrid: Santillana). 
declinando el honor". Las delicadas relaciones “entre el Gobierno del noble pueblo alemán (Gobierno y pueblo a quienes tan agradecidos vivimos) y la Santa Sede" impedían "la presencia de un sacerdote en el Congreso, de no tener preventivamente el 'placet' del representante de Su Santidad", Ildebrando Antoniutti, llegado a la España sublevada a finales de julio de 1937. Así que su conclusión era clara:

"De no tener V. ese PLACET preventivo, yo me debo oponer, y con toda la fuerza de mi autoridad me opongo a que asista al referido congreso, para evitar el peligro de causar una pena a nuestro Santísimo Padre el Papa". ${ }^{65}$

El obispo se curaba en salud invocando la contrariedad del Papa. No argumentaba que el nazismo fuese una ideología perversa, ni que debía prevenirse el indudable uso propagandístico de la presencia en el Congreso nazi de un cura católico encargado de la prensa y la propaganda de Falange. Por escrito, le bastaba con decirle tajantemente que no y, tal vez, recordarle de palabra todo lo que omitía decir el diario que dirigía el sacerdote falangista: que la persecución anticatólica en Alemania chocaba con su asistencia al congreso nazi de Nuremberg, y que no aceptaría hechos consumados, como había ocurrido con su nombramiento.

Llovía sobre mojado para Olaechea. Este asunto aumentaba su sorda irritación ante la independencia de un Franco que nombró al cura para un cargo político, sin consultarle: "a mí me causó verdadero disgusto y creí un desacierto el que se dispusiera de él”, le dijo Olaechea al gobernador civil de Pamplona, al responder el 5 de septiembre a su carta de agosto. El obispo lamentaba "esas contrariedades por la actuación de los sacerdotes, [que] se evitarían por completo, si nuestras dignas Autoridades, no dispusieran de ninguno de ellos, para cargos ajenos a su misión sacerdotal (como lo son todos los cargos políticos) sin previo aviso y consentimiento de los respectivos Prelados", incluso aunque el nombrado fuera "un sacerdote digno, como lo es DON FERMÍN IZURDIAGA", pues ocurría que "el sacerdote tiene una misión muy especial y sacado de ella suele él sacar todas las cosas de quicio". 66

Consciente del riesgo de perder el escudo de su obispo, el sacerdote le agradeció "su amable carta de hoy aprobando mi conducta de no asistir al Congreso de Alemania. Nunca pensé en hacerlo por la única razón de ser Sacerdote Católico". Además, apuntaba, entre otras, estas dos cuestiones de interés:

"Era esta alta invitación de Hitler una manera de "cultivarme" o "amansarme" ya que en este mes he prohibido se formara en Falange un grupo de intelectuales "Carlos V" con su revista correspondiente que trataba de influir, nada menos que en la constitución del Nuevo Estado y era fletada por la "embajada de Alemania". No tenga VE. dudas: estoy y estaré firmísimo en la Fe... y en la Moral. [...].

"Haré todo lo posible mañana lunes por visitarle. Necesito de su palabra pues llevo tres semanas de mucho trabajar y moverme. Pero estoy contento. He tenido el jueves [¿el 2-IX?] una entrevista de cuatro horas con el Generalísimo y conforta totalmente la presencia y el sentido de nuestro Héroe". ${ }^{67}$

${ }^{65}$ ADP, GD, Olaechea a Yzurdiaga, 4-IX-1937; cursivas anteriores, en el original.

${ }^{66}$ ADP, GD, Olaechea a De la Rocha, 5-IX-1937.

${ }^{67}$ ADP, GD, Yzurdiaga a Olaechea, sin fecha, posiblemente 4-IX-1937. Lo mismo afirma Payne, Stanley G. 1986. Falange. Historia del fascismo español: 181 Madrid: Sarpe, cuya fuente sobre el particular es una entrevista con el mismo Yzurdiaga. 
El sacerdote cultivaba a Olaechea exponiéndole sus andanzas político-culturales, inquieto por su precariedad canónica y por el riesgo que supondría cualquier duda del obispo sobre la rectitud de su intención y la eficacia de sus resultados. Y, más todavía, cuando había de por medio una materia tan sensible como la paganización por influencia alemana que algunos obispos temían ocurriese en la "Nueva España" o en Falange. ${ }^{6}$

La adhesión al Héroe era en Yzurdiaga tan entusiasta en privado como en público, como prueban las elogiosas páginas que Arriba España dedicaba al César Francisco Franco. Y entronca con las garantías que el entero mundo eclesiástico español tenía y ofrecía al Vaticano sobre el genuino catolicismo de Franco y, por tanto, acerca de las diferencias entre la situación alemana y la española. Garantías que Franco mismo ofrecía directamente a la Santa Sede en sus entrevistas con Mons. Antoniutti. ${ }^{69}$ En aquel otoño de 1937, el primado Isidro Gomá o el obispo de Pamplona dudaban entre el temor a la influencia nazi en España y la confianza en que esto fuese neutralizado por Franco y sus ayudantes, entre ellos el falangista Yzurdiaga.

En relación con éste, Marcelino Olaechea abandonó su pasiva irritación y sorda tolerancia, su laissez faire en torno a su oficio político. Una lacónica carta, de 7 de octubre de 1937, convocó a Yzurdiaga con urgencia a su Palacio episcopal. ${ }^{70}$ Lo que le transmitió entonces lo escribió al día siguiente a Franco:

"Excmo. Sr.

"El sacerdote Fermín Izurdiaga Lorca, actual Delegado N. de Prensa y Propaganda de Fet de las Jons, va a pedir a Vuecencia, por indicación mía, la gracia de verse libre del referido cargo.

"De ser posible, yo la celebraré en el alma; pues creo ha terminado la labor útil que podía realizar el sacerdote -en un puesto tan ajeno a su misión-; y que se recogerán muy mejores frutos, si la continúa un seglar.

"Por otra parte, será un gran bien para Don Fermín Izurdiaga -que es tan excelente sacerdote- el poderse reintegrar, como él desea, a la serenidad de su ministerio sacerdotal". ${ }^{71}$

No aportaba el obispo razones. Ni siquiera la de la tardanza e incumplimiento de la promesa de solicitar su venia. Quizá Ildebrando Antoniutti, que ese 7 de octubre presentó en Burgos sus cartas como Encargado de Negocios de la Santa Sede ante la España de Franco, presionó a Olaechea para zanjar el caso Yzurdiaga, aunque sobre esto no hay pruebas tan tempranas; o quizá lo hiciese el primado Gomá, nada partidario de la continuidad del cura navarro en aquel puesto por las zancadillas que la Delegación que Yzurdiaga presidía estaba poniendo a algunas publicaciones católicas. ${ }^{72}$

${ }^{68}$ Sobre el particular, abundan las referencias en el epistolario de Gomá con la Santa Sede, desde la segunda mitad del año 37: cfr. J. Andrés-Gallego, y A. Pazos. 2004-2005. Archivo Gomá. Documentos de la Guerra Civil: Madrid: CSIC, vols. 6 a 8 (en adelante, AG, seguido del volumen, fecha y páginas). Sobre el particular, Martínez Sánchez, S. 2011. "El episcopado español ante la encíclica Mit brennender Sorge, 19371938”, en Á. Barrio Alonso, J. de Hoyos Puente, R. Saavedra Arias (eds.), Nuevos horizontes del pasado. Culturas políticas, identidades y formas de representación, Santander: Ediciones de la Universidad de Cantabria, comunicación electrónica http://www.ahistcon.org/docs/Santander/contenido/indice-mesa6.html).

${ }^{69}$ Cfr. Botti, A. 2010. "Santa Sede e influenza nazista nella Spagna durante la guerra civile nei documenti dell'Archivio Segreto Vaticano. Un ruolo anti-totalitario della Chiesa?", en A. Guasco, R. Perin (eds.), Pius XI: Keywords: 112-115 Zurigo-Berlino: Lit.

${ }^{70}$ ADP, GD, Olaechea a Yzurdiaga, 7-X-1937.

${ }^{71}$ ADP, GD, Olaechea a Franco, 8-X-1937.

${ }^{72}$ Esta razón la ofrece Andrés-Gallego, J. 1997: 44-45. 
En algún momento posterior, Olaechea le resumió al obispo de Gerona las etapas principales del affaire, aludiendo a "Urgencia mía para verse libre del cargo D[on]. F[ermín]. a mediados de octubre", ${ }^{73} \sin$ más explicaciones. Pudo ser esto lo que sorprendiese a Franco, que las demandó el 9 de octubre a Gomá y a Olaechea. Su carta al Primado revela a las claras que no quería prescindir de don Fermín salvo que hubiese razones ocultas que le hiciesen indigno, pues en lo doctrinal no le parecía que hubiese mejor candidato:

“[...] Quiero por ello manifestar a VE que de no existir motivo de orden sacerdotal -que yo respetaría muchísimo- no le ponga impedimento para el ejercicio de aquella actividad ya que dándose en él la coincidencia feliz -en esta hora de encauzamiento-de su condición eclesiástica y la de viejo luchador de la Falange, conservando la pureza de espíritu de ésta, contribuye a mantener el sentido católico, que, en cuanto constitutivo de nuestra nacionalidad, debe presidir toda política auténticamente española.

"De existir alguno de los antes supuestos motivos, con toda libertad por su parte y por la mía reserva, puede manifestarlos". ${ }^{74}$

A Marcelino Olaechea también le escribió el Caudillo ese mismo 9, muy lacónicamente. Salvo razones canónicas, Franco no se creía que Olaechea le tuviese por excelente sacerdote, "agradecería no pusieran traba o impedimento" para que Yzurdiaga siguiese en el cargo ${ }^{75} \mathrm{Y}$ el obispo cedió. No se ha conservado su respuesta a esta carta de Franco pero, en otra tardía a Yzurdiaga repasando la historia de las tensiones, don Marcelino aclaraba que si le autorizó fue en consideración con Franco, aunque "manifestando la esperanza y el deseo que se le librara a V. cuanto antes del cargo": ${ }^{76}$ a lo que parece, cedió a cambio de la promesa de encontrarle pronto un sustituto.

Por el contrario, Gomá era más tajante. El primado y arzobispo de Toledo, que tenía su residencia entonces en Pamplona y allí se veía con Olaechea y conocía de primera mano dimes y diretes sobre Yzurdiaga, era rotundamente contrario a transigir en este asunto. El 13 de octubre dijo a Franco por escrito que había hablado "varias veces" con Olaechea sobre el cura azul, "dándole mis impresiones por vía de simple consejo". Desde luego, no conocía desliz moral alguno en él, pero sí "actuaciones inoportunas", por razones "de disciplina y de carácter" de Yzurdiaga, que el mismo Antoniutti había presenciado y animado a su obispo "a amonestar severamente". Debía abandonar su cargo por una simple cuestión de principios:

“C) el espíritu del derecho eclesiástico y las exigencias de la disciplina reclaman la ausencia de los sacerdotes de toda intervención política; más todavía una intervención de organización y mando como ejerce el Sr. Izurdiaga. No es improbable que por la autoridad eclesiástica se tomen a no tardar medidas radicales en este punto. Por ello tal vez sería conveniente que se buscara la forma de sustituir oportunamente al Sr. Izurdiaga en el cargo que ejerce. Con todo, no creo tenga el Sr. obispo de Pamplona inconveniente en que se retrase la solución el tiempo necesario para hallar un sustituto seglar que pueda reemplazar hasta con ventaja al Sr. Izurdiaga. Éste debió requerir la autorización de su prelado antes de aceptar el cargo político que desempeña, y seguramente no se le hubiera otorgado". ${ }^{77}$

${ }^{73}$ ADP, GD, Olaechea a Cartañá, sin fecha.

74 ADP, GD, Franco a Gomá, 9-X-1937. También, Andrés-Gallego, J. 1997: 45-46. Esta carta no aparece en el volumen correspondiente (el 8) del Archivo Gomá.

${ }^{75}$ ADP, GD, Franco a Olaechea, 9-X-1937.

${ }^{76}$ ADP, GD, Olaechea a Yzurdiaga, 9-XII-1937.

77 ADP, GD, Gomá a Franco, 13-X-1937. Esta carta no está en Archivo Gomá ni en Andrés-Gallego, J. 
Gomá, que señalaba a un Yzurdiaga muy independiente como responsable de aquel asunto torcido, también afeaba a Franco que no hubiesen consultado a los obispos implicados antes de nombrarle: a Olaechea por supuesto, pero también a él mismo, que bien lo merecía como primado y representante oficioso de la Santa Sede cuando se produjo el nombramiento. Aquello podía proseguir algún tiempo más pero no indefinidamente, hasta que Franco quisiera, porque Yzurdiaga era sacerdote ante todo, y debía obedecer a su obispo y recibir encargos pastorales y no políticos. En fin, la jerarquía eclesiástica, se concluía de su carta a Franco, era inocente en un episodio que a Gomá le parecía sencillamente penoso.

Su seguridad sobre qué habría hecho antes el obispo de Pamplona o qué iba a decidir ahora venía de sus conversaciones con el propio Olaechea. Por eso, sorprende que cuando

Yzurdiaga comunicó a su obispo, el 21 de octubre, su nombramiento para el Consejo Nacional de Fet y de las Jons, según anunciaba ese día la prensa, don Marcelino le diese su licencia para ocupar un cargo donde "he de continuar con más ardor y más efectividad la única aspiración de toda mi vida: la Grandeza de la Iglesia y de España" ${ }^{78}$ Yzurdiaga tuvo el beneplácito del obispo de Pamplona al día siguiente, sin demoras ni cautelas. Más aún, Olaechea parecía completamente a favor:

"Recibo su carta, que le agradezco.

"Le agradezco también la delicadeza; pues en realidad no necesitaba nuevo "placet" de mi parte, ya que en virtud de su cargo de Delegado Nacional de Prensa y P. entra V. por derecho a formar parte de "El CONSEJO NACIONAL".79

"Abre el Señor un campo más ancho a su actividad; y tengo la seguridad de que la Iglesia se alegrará de su gestión.

"Cuente con las oraciones y todo el afecto de su afmo. amigo". 80

En dos semanas escasas, Marcelino Olaechea había pasado de pedir a Franco su cese fulminante a aceptar de buen grado que Yzurdiaga se integrase en el órgano consultivo de la Falange unificada, dando un nuevo plácet que, además, estimaba innecesario. Su cambio se explica sólo por la carta de Franco del 9 de octubre: finalmente la máxima autoridad de la España sublevada le pedía el plácet que Olaechea deseaba. En esta conducta un tanto zigzagueante, el obispo creía útil la presencia temporal del sacerdote navarro en los engranajes de la España franquista. Un matiz no pequeño a la afirmación de Gomá a Franco de que Olaechea habría denegado su placet de habérselo solicitado al inicio de todo el asunto. ${ }^{81}$

Gomá subestimó la confianza de don Marcelino en Yzurdiaga, a quien su obispo tenía por un hombre excelente y díscolo, aunque dócil y, por eso, controlable. Y Olaechea infravaloró a su vez la capacidad del sacerdote falangista de ir por libre. Cuando esto ocurrió, a finales de octubre de 1937, se

1997.

${ }^{78}$ ADP, GD, Yzurdiaga a Olaechea, 21-X-1937.

${ }^{79}$ El obispo creía mal. En los Estatutos de Fet de las Jons, del 4 de agosto de 1937, se indicaba (art. 36) que Franco nombraría a sus miembros y que podría "en cualquier momento sustituirlos o deponerlos individualmente", sin vincular determinados puestos con el cargo de Consejero (cfr. Boletín Oficial del Estado, núm. 291, 7-VIII-1937, p. 2741).

${ }^{80}$ ADP, GD, Olaechea a Yzurdiaga, 22-X-1937. Por el contrario, la irritación de Gomá era considerable ante el nombramiento "del fulano" (AG 8: Gomá a Cartañá, 21-X-1937, 155-156).

${ }^{81}$ Desde luego, el cardenal primado mostró a Olaechea su desagrado por esta autorización a Yzurdiaga (cfr. Andrés-Gallego, J. 1997: 64). 
cuarteó la confianza de Olaechea en aquel sacerdote, al creer falaz la jactancia sobre la catolización de la Falange con la que hablaban Yzurdiaga y sus amigos, a la vista de la siguiente serie de hechos. Así pues, el propio Fermín Yzurdiaga consiguió que los recelos de Gomá se impusieran a la benévola tolerancia de Olaechea y que ambos, espoleados por el Encargado de Negocios de la Santa Sede, exigieran su retirada de la escena pública.

\section{EL SUEÑO SE DERRUMBA}

Los pescozones le llegaron a Yzurdiaga en cascada, entre octubre y noviembre de 1937. En conjunto, no parece que echase un pulso a alguien: más bien, no previó las duras consecuencias de embarcarse en aquellas aventuras. Pero esta explicación sea tal vez ingenua. De seguro, creía suficiente el respaldo de Franco y de su hombre fuerte, Ramón Serrano Súñer, para sortear el posible fuego cruzado de la autoridad eclesiástica, si es que ésta salía al paso de las tres iniciativas que emprendió, como en efecto ocurrió: al final, se le aplicó la sentencia evangélica de que no se puede servir a dos señores.

Las tres cuestiones tenían que ver con su cargo en la jefatura de Prensa y Propaganda. El primer asunto tocaba a la Prensa. En concreto, su Delegación Nacional incautó y suspendió sine die el semanario infantil Pelayos editado en San Sebastián. El pretexto fue que el dibujo de la portada del tercer número de octubre del 37 mostraba a un requeté venciendo a un rojo con camisa azul. Celestino Minguela, el Secretario de la Delegación, comunicó a la revista que se incautaba el número "tendencioso", por hacer "campaña francamente derrotista contra la Unificación". ${ }^{82}$

El obispo pidió a Yzurdiaga los papeles sobre este affaire, aunque desconozco si Olaechea llegó a intervenir, o si lo hizo con la misma contundencia que el primado Gomá. Éste no tragaba al cura azul: decía de él que carecía de "la medida requerida en estas altas funciones", 83 o que "no creo tenga remedio: es un testaferro" útil "para menesteres menos finos", a quien le convenía "a lo menos un buen palo, aunque sea con nocturnidad y alevosía". ${ }^{84}$

Yzurdiaga no tenía unas relaciones muy cordiales con el entouraga de Gomá en Pamplona, compuesto por su secretario Luis Despujol y el obispo de Gerona, allí refugiado. En esas fechas finales de octubre del 37, a Olaechea le llegaron noticias confusas sobre una agresión verbal o física de Yzurdiaga y unos falangistas a Despujol, en la sacristía de la iglesia de los Redentoristas, en Pamplona. ${ }^{85}$ Gomá había enviado a Despujol a San Sebastián a arreglar lo de Pelayos y éste volvió aconsejando no "tolerar dictaduras de segunda fila" y "apartarle de las actividades actuales", porque podía "acarrear serios disgustos". ¿Llegó algo de eso a Yzurdiaga, que procedió a resolver sus diferencias de una forma un tanto ruda?

${ }^{82}$ ADP, GD, Celestino Minguela a la revista Pelayos, 25-X-1937. Cfr. Andrés Gallego, J. 1997. "La muerte de Pelayos y el nacimiento de Flechas y Pelayos (1938)". Hispania Sacra 49: 87-113; y Herrero Suárez, H. 2007. Un yugo para los flechas. Educación no formal y adoctrinamiento infantil en Flechas y Pelayos: 27-44 Lleida: Milenio.

83 Archivio Segreto Vaticano (ASV), Nunziatura Madrid (NM), nº 970, folio (fol.) 36: Gomá a Antoniutti, 27-X-1937.

${ }^{84}$ AG 8: Gomá a Despujol, 29-X-1937, 227; y Gomá a Cartañá, 1-XI-1937, 243.

${ }^{85}$ ADP, GD, Olaechea al superior de los Redentoristas, 26-X-1937.

${ }^{86}$ AG 8: Despujol a Gomá, 1-XI-1937, 248. El superior de los Redentoristas informó a Olaechea que Yzurdiaga le dijo al sacristán que "voy a darle de bofetadas a Don Luis Despujol; no hay derecho a calumniar"”. Aunque no llegaran a las manos, el episodio debió de ser violento. 
El segundo asunto era sobre Propaganda. Su Delegación cursó una circular a los periódicos falangistas el 12 de octubre de 1937, dando consignas para preparar la Fiesta de los Caídos, que se celebraría con especial solemnidad por vez primera el 29 de octubre. Fiel a sí mismo, la circular hablaba de los enemigos en los frentes y de otros "metidos en nuestra propia tierra, en nuestra misma casa", ordenaba insertar entrefiletes en los periódicos y ofrecía guiones para los editoriales del 19 al 29 de octubre. Esos guiones eran una síntesis sobre la naturaleza de la Falange y su misión para la Unidad, la Nación, la Religión y el Imperio españoles.

Los sueltos sobre el catolicismo, que se insertaron en la prensa el 23 de octubre, molestaron profundamente a Olaechea y a Gomá. El primero le dijo a Franco que eran "formas de hablar y suspicacias (Circular num. 47) que jamás se pueden pasar en un sacerdote". 87 Para Gomá, la circular era un "enorme desplante" que bordeaba "los lindes de la injuria a la Santa Iglesia" ${ }^{88}$ Los entrefiletes eran éstos:

"NO ADMITIREMOS EN EL ESTADO NACIONALSINDICALISTA NINGUNA POLÍTICA ENEMIGA Y MENOS AQUELLA QUE SE DISFRACE CON ASPECTOS DE RELIGIÓN. LA RELIGIÓN NO PUEDE SER YA EN ESPAÑA INSTRUMENTO DE PERTURBACIÓN EN MANOS DE POPULISTAS, DE MASONES Y DE ANORMALES"

"QUEREMOS LITURGIA, EVANGELIO, SANTIDAD, NO PARODIAS, NO FOLLETOS, NI POLÍTICAS CON ASPAVIENTOS DE RELIGIÓN"

"YA ES HORA DE QUE TENGAMOS UNA RELIGIÓN DE APÓSTOLES, NO UNA RELIGIÓN DE ABATES"

"LA RELIGIÓN EN ESPAÑA NO DEBE SER UNA ESTADÍSTICA SINO UNA LLAMA, NO UNA SECCIÓN DE FICHEROS, SINO UN IMPULSO DE SANTIDAD". "NO CONCEBIMOS UNA DIPLOMACIA DE LA IGLESIA SI NO ESTÁ SOSTENIDA POR ESTA ÚNICA COSA: LA BUENA FE". ${ }^{89}$

Esta gota colmó el vaso de la paciencia de Olaechea. El obispo redactó un guión de sus razones para rogar "ardientemente a S.E. el Generalísimo sea sustituido cuanto antes el Rvdo. Sr. Don Fermín Izurdiaga Lorca". Franco, que le recibió en audiencia en Burgos al iniciarse noviembre del 37, le escuchó estas ideas: que el cargo se prestaba a no vestir la sotana en los actos públicos; que desprestigiaba "el buen nombre sacerdotal cargando sobre él los deslices de la Prensa"; que exponía a formas de hablar impropias de un clérigo; y, finalmente, que "el agitado ambiente de la Prensa y la Política desvía naturalmente de su misión a un sacerdote". ${ }^{90}$ No contento ni seguro del resultado, Olaechea repitió lo mismo "con toda decisión y urgencia, en una larga y muy grata entrevista, al Sr. Don Ramón Serrano Súñer, a quien volví a recordar por carta y pocos días después, el asunto de su sustitución". ${ }^{1}$ Serrano defendió la continuidad de Yzurdiaga, de palabra y por escrito (el 13 de noviembre del 37), excusando su retraso:

"Del otro asunto espero hablar mañana o pasado con el Sr. Cardenal [Gomá]. Cuando Vuecencia o Su Eminencia consideren inaplazable la sustitución tendrá que plantearse ésta por

\footnotetext{
${ }^{87}$ ADP, GD, guión de ideas de Olaechea, sin fecha.

${ }^{88}$ ADP y AG 8: Gomá a Olaechea, 6-XI-1937, 300.

${ }^{89}$ ADP, GD; y AG 8: 255-256.

${ }^{90}$ ADP, GD, guión de ideas, sin fecha. Cursivas, en el original.

${ }^{91}$ ADP, GD, Olaechea a Yzurdiaga, 9-XII-1937.
} 
virtud de esa superior consideración, ya que nosotros, por las razones que ampliamente le expuse, desde el punto de vista político, considerábamos interesantes unos servicios que la persona en cuestión prestaba con lealtad". ${ }^{92}$

La respuesta de Mons. Olaechea al que ya era la mano derecha de Franco se demoró hasta el 26 de noviembre. Su carta muestra cierta irritación por no saber nada sobre el prometido relevo, y porque Serrano en su carta se hubiese hecho el distraído sobre el asunto. Olaechea debía de estar harto de ese juego del gato y del ratón, y se reafirmó en lo dicho:

"Le confieso que desde mi regreso de Burgos he venido abrigando la esperanza de que apareciera de un día a otro la noticia de esa sustitución; y he venido rogando al Señor que le inspirara cuanto antes y con el mayor acierto el nombre de un seglar que continuara, mejorándola, la obra de Don Fermín de Izurdiaga.

"Él conoce mi deseo y lo hace suyo. Tendrá una gran alegría al saber que por disposición de su Prelado, no debe aplazarse su sustitución.

"De que ella traerá un mayor bien a la Iglesia (por el cumplimiento filial de sus leyes) estoy cierto; pero no me cabe tampoco la duda de que lo traerá también a la Patria". ${ }^{93}$

Yzurdiaga tenía una particular manera de "hacer suyo" aquel "deseo" de reducir su protagonismo. Más bien, hizo suya, porque la tenía como propia, la labor propagandística de elogiar en la España de Franco los éxitos de la Falange. Así lo revela su tercera iniciativa, que convenció a los eclesiásticos que debían imponerse a Franco y a Serrano en aquel pulso de nervios en torno a alguien que parecía ser la pieza clave de un negociado decisivo.

El sábado 28 de noviembre, el joven sacerdote pronunció un discurso en Vigo ante las "Gloriosas e ilustres representaciones de Portugal. Excelentísimas Autoridades Militares y Civiles. Falanges de Galicia". El discurso se radió a toda la zona franquista. Como trajo cola y bastantes críticas a Yzurdiaga que también llegaron a su obispo, el sacerdote le envió una copia indicándole que se fijase "en el párrafo que se habla del espíritu", que había recuadrado, porque "todo es perfectamente ortodoxo. Es lo único que me interesa quede ¡muy claro!". También le precisó que "con ese texto que le envío puede contestar a los denunciantes, que leyeron "oído" demasiadas cosas en mi discurso". ${ }^{4}$ Éste era el texto:

"Pues enfrente de esta revolución ferozmente negativista yo creo en la revolución de los espíritus como una juventud maravillosa de los pueblos. El espíritu de una llama eterna, sobrenatural, vehemente y violenta -más violenta que la fuerza ciega de las pistolas- que ilumina, que mueve, que arrastra el gobierno de los mundos. Pues la Falange en estas horas augustas de su silencio renueva su vigor entrañablemente con el poder del espíritu”.

Pero en Vigo no sólo había hablado de la revolución de los espiritus. También mencionó a Hitler, "caudillo de la raza alemana, que al volverse a la vieja historia de su pueblo, se encuentra con las selvas vírgenes, con los dioses Nibelungos y con el dios Votán". Esta frase no le pareció importante y por eso no la resaltó en su texto a Olaechea, por creerla tal vez un recurso efectista, una licencia poética. El elogio al vínculo entre Hitler y las divinidades paganas era chocante en labios de un sacerdote católico, pero no en la pluma de un falangista que dirigía un periódico que continuamente incensaba a ese otro Héroe o César que era Hitler.

\footnotetext{
92 ADP, GD, Serrano Suñer a Olaechea, 13-XI-1937.

${ }^{93}$ ADP, GD, Olaechea a Serrano Suñer, 26-XI-1937.

${ }^{94}$ ADP, GD, Yzurdiaga a Olaechea, sin fecha.
} 
Esta dualidad radicaba en su afán por construir una Falange confesional y por expandir el control falangista sobre la España sublevada. ${ }^{95}$ Pero exponía sus actuaciones a las críticas y hacía frágiles y ambiguas sus palabras, justo cuando era observado con mucha atención. Desde luego, por su obispo, incómodo porque la prolongación de su cargo, sin que Franco le cesara, permitía al sacerdote hacer de las suyas o actuar protegido por el consentimiento de Olaechea, cuando asistió en Burgos a la jura de su cargo como Consejero Nacional del Movimiento, el 2 de diciembre.

Don Marcelino se tomó unos días para decidir y el 9 de diciembre dio por acabada la responsabilidad propagandística de su sacerdote mediante cartas al interesado, a Serrano Suñer y a Franco. Al primero hizo una síntesis de sus gestiones entre mayo, cuando supo por la prensa de su nombramiento, y el presente momento, en que tomaba la decisión "que con esta carta le impongo":

"Vuelva a presentar y a la mayor brevedad posible su dimisión irrevocable del cargo de Delegado N. de P. y P. de Fet. de las Jons y de todos sus corolarios e inherencias de modo que el día de Navidad se halle V. libre de esas amarguras y preocupaciones, pues desde ahora y para aquel día considero ese cargo y sus corolarios e inherencias incompatible con sus Licencias ministeriales y con la obediencia y respeto debidos a mi autoridad.

"Doy cuenta de esta mi resolución a S.E. y a Don Ramón Serrano y Suñer. Creo que le hago un bien y le doy un consuelo". ${ }^{96}$

Los "corolarios e inherencias" eran el puesto de consejero nacional, que Olaechea tampoco quería que mantuviese. Su mensaje a Serrano fue muy corto. Si hubiese alguna duda de la necesidad de removerle del cargo, le decía, "las incidencias de su desarrollo (alguna muy reciente) persuadirían a cualquiera". Así que consideraba aquellos puestos "incompatibles con sus Licencias ministeriales y con la obediencia y respeto a mi autoridad". ${ }^{97}$ Lo mismo repitió a Franco: no podía continuar en esos cargos. Fue una presión coordinada, porque Ildebrando Antoniutti también insistió en ese mensaje días después, ${ }^{98}$ respaldando esto que Olaechea le decía por escrito al General:

"Nuevos detalles de esa gestión y el parecer concorde de quienes me asesoran, me ponen en el deber de urgir a Don Fermín I. para que presente su dimisión; y así acabo de imponérselo dándole de plazo hasta el día de Navidad, pues desde hoy y para ese día tengo el dolor de considerar incompatible con sus Licencias Ministeriales el referido cargo con sus corolarios y naturales inherencias". ${ }^{99}$

Franco, algo molesto, aceptaba cesarle como Delegado de Prensa y Propaganda, pero no iba a prescindir de Yzurdiaga en esos "corolarios y naturales inherencias":

"Si con ello se refiere al cargo de Consejero Nacional, tengo que decir en primer término que éste no es corolario ni inherencia del de Jefe de Prensa y Propaganda, y que por su

${ }^{95}$ El Arriba España, 9-XII-1937, publicó en su contraportada el final de su discurso en Vigo, cuando afirmó que "cueste lo que cueste hay que edificar un estado nacionalsindicalista sobre estos tres postulados: la Fe, el Imperio y el Nacionalsindicalismo (una enorme ovación subraya la frase del orador)".

${ }^{96}$ ADP, GD, Olaechea a Yzurdiaga, 9-XII-1937.

${ }^{97}$ ADP, GD, Olaechea a Serrano Suñer, 9-XII-1937.

${ }^{98}$ A través de Sangróniz, jefe del Gabinete diplomático de Franco, Antoniutti comunicó el interés de la Santa Sede de evitar que un sacerdote con rango oficial en la Falange difundiera teorías y noticias opuestas a los principios de la Iglesia (ASV, NM, nº 968. fasc. 6, fol. 577: despacho a Pacelli, 16-XII-1937).

${ }^{99}$ ADP, GD, Olaechea a Franco, 9-XII-1937. 
naturaleza consultiva no podrían convenirle las discutibles objeciones que a otro cargo político activo pudieran hacerse". ${ }^{100}$

Serrano tampoco parecía especialmente entusiasmado cuando le decía al obispo que "después de la carta del Generalísimo yo nada tengo que contestar a V.E. que, además, conoce nuestros puntos de vista" concordes. Por eso, escribía muy seguro que "nos parece una equivocación su decisión" y que Yzurdiaga no la recibía "con aquella alegría que V.E. pensaba; y yo me lo explico". ${ }^{101}$

Ante la resistencia, Olaechea volvió a insistirles, a vuelta de correo. Les escribió de nuevo el 18 de diciembre. A Serrano le dijo que había "graves razones, que arrastran indeclinablemente mi voluntad"; que no era su capricho, sino "las leyes de la Iglesia, la voluntad de la Santa Sede y lo que decidirían todos mis Venerados Hermanos, los Obispos de España"; y que le apenaba "no poder, en este asunto, servir al que, elegido por Dios, cuenta con el tributo de cuanto soy y tengo". ${ }^{102}$ Más claro fue con Franco. No quería el obispo "consentir que siga teniendo Don Fermín I. otra tribuna que no sea el púlpito de las iglesias", el lugar apropiado para quien conocía, estimaba y protegía bastante bien:

"Don Fermín es bueno: tiene noble intención; gran corazón y fantasía; pero todo ello en una desproporción monstruosa con la disciplina mental, propia de un sacerdote. En el calor de un discurso (o de una redacción) ante una muchedumbre de dispuestos que le aplaude, suelta las amarras de la inteligencia sacerdotal para cabalgar en alas de la poesía y del corazón, rozando y chocando con la moral y el dogma. Su último discurso en Vigo ha sido algo de escándalo nacional; produciendo asombro el que un sacerdote dijera tales cosas, y que su Sr. Obispo no le haya retirado las Licencias Ministeriales. Se ha pensado llevar dicho discurso al tribunal del Santo Oficio. ${ }^{103}$ Yo he trabajado para que no se hiciera, pues quiero evitarle todo dolor (porque me consta de su buena fe), todo dolor, que no sea el que yo le dé, que le conozco y le quiero. En otro hombre, los párrafos sobre "la revolución de los espíritus" serían condenados como saturados de panteísmo idealista; en otro hombre, su alusión al Fhurer [sic], que "al volverse a la vieja historia de su pueblo, se encuentra con las selvas vírgenes, con los dioses Nibelungos, con el dios Votán" serían un sarcasmo a la tristeza de los buenos católicos de Alemania. En Don Fermín son "palabras, palabras, palabras"; pero Don Fermín es sacerdote católico y sus palabras no pueden ser más que un eco del Evangelio; no una confusión o un daño de las almas. La sotana ata; ata, por la misericordia de Dios, muy fuertemente; y ni aun lo que puede decir un buen seglar puede, a veces, decirlo un sacerdote; que ha de guardar siempre aquella serena y suave caridad que le impone su ministerio". ${ }^{104}$

Por esas razones y porque el caso Yzurdiaga "tiene ya resonancias en plano superior a mi autoridad", tampoco autorizaba Olaechea "con mi placet, o con mi silencio", que el sacerdote fuese consejero nacional, porque le dejaría al descubierto ante sanciones canónicas "que yo no sería capaz de levantar; y que habrían de traernos muy mayores y justas angustias". Olaechea no hablaba por hablar:

${ }^{100}$ ADP, GD, Franco a Olaechea, 14-XII-1937.

101 ADP, GD, Serrano Suñer a Olaechea, 14-XII-1937. No es fácil explicar por qué Serrano omite explicar en sus "memorias" este episodio de los inicios de su gobernanza: quizá tenga que ver con su afirmación de ser "un personaje inventado" (Saña, H. 1982. El franquismo sin mitos. Conversaciones con Serrano Suñer: 26 Barcelona: Grijalbo).

${ }^{102}$ ADP, GD, Olaechea a Serrano Suñer, 18-XII-1937. Hay dos borradores algo distintos de su carta a Serrano, fechados el 17 y 18 de diciembre. Entiendo que debió de fechar la carta el 18, pero no estoy seguro.

${ }^{103}$ No he encontrado rastro documental sobre esto: tal vez fueran conversaciones con Gomá o Antoniutti, o sugerencias al obispo de alguno de los damnificados por las críticas periodísticas o la actuación propagandística del cura azul. Pero lo de llevarle al Santo Oficio quedó en nada, como se lee.

${ }^{104}$ ADP, GD, Olaechea a Franco, 18-XII-1937. 
en esas mismas fechas, Antoniutti informaba a la Secretaría de Estado del vínculo entre Yzurdiaga y la propaganda pronazi y aconsejaba apartarle de su puesto, para "non permettere degli equivoci in un campo tanto delicato come quello della propaganda, ed in un momento tanto critico come il presente". ${ }^{105}$

Le gustase o no, Yzurdiaga obedeció la orden de su obispo y presentó su dimisión antes de la Navidad de 1937. Y éste se lo agradeció el 22 de diciembre, le deseó unas felices Navidades ya "alejado de la responsabilidad y preocupaciones que tantas amarguras le han debido causar" y se despidió de él recordándole esto:

"Por tanto, presentada la dimisión de estos cargos, como lo hizo, debe V. obrar, desde el día de Navidad, como si los hubieran aceptado ([la dimisión de] los cargos y sus consecuencias), para obedecer a lo que le impuse y gozar de sus Licencias ministeriales". ${ }^{106}$

\section{¿UN YZURDIAGA DIFERENTE?}

Nueve meses habían durado sus andanzas por las cimas del poder en la España franquista. Claro que aún conservaba en sus manos un arma como Arriba España y la pasión política que le condujo hasta esa destacada influencia nacional. Además, entre sus amistades políticas se contaban Serrano Suñer y Franco, que se resistieron varias veces a prescindir de un servidor considerado útil, leal y eficaz. En definitiva, sería una simpleza concluir que su dimisión le recluía en una esfera pastoral o religiosa.

Enfrente, su obispo Olaechea, el primado Gomá y el diplomático Antoniutti estaban decididos a desactivar aquella influencia política, convencidos de que su deriva ideológica y sus actuaciones eran algo más que anécdotas pintorescas o episodios pasajeros, que podían pasarse por alto. Es incluso probable que Gomá y Antoniutti le viesen como un ariete para incrustar entre los católicos la aceptación de unos fundamentos ideológicos, de carácter fascista o nazi, para la España nueva de Franco $^{107}$. Que creyesen que las empresas de Yzurdiaga tuviesen ropajes católicos, de ahí sus continuas declaraciones de fidelidad a la Iglesia, pero alma totalitaria o sospechosa de serlo.

El 17 de enero de 1938, Antoniutti transmitió al obispo Olaechea la preocupación de la Santa Sede por las actividades de Yzurdiaga. En particular, extrañaban las expresiones de un "contenuto teologico poco rassicurante" en sus discursos o artículos, y desagradaba que actuase al margen de su obispo. Por eso, Antoniutti felicitó en nombre de la Santa Sede a Olaechea, "per ricondurre lo stesso sacerdote alla osservanza dei suoi doveri". Y le rogó que vigilase atentamente y actuase "se

${ }^{105}$ ASV, Affari Ecclesiastici Straordinari (AES), Spagna, fasc. 322, fols. 30-31: despacho de Antoniutti a Pacelli, 26-XII-1937.

${ }_{106}$ ADP, GD, Olaechea a Yzurdiaga, 22-XII-1937.

${ }^{107}$ Desde luego, la simpatía de Yzurdiaga hacia el nazismo fue patente durante 1937. El Arriba España ofrecía a diario alguna o varias noticias sobre diversos temas de la Alemania nazi: la geografía y la cultura alemanas; su resurgir militar y científico; en portada, la referencia o amplios extractos de discursos de Hitler; elogios a su política internacional; datos sobre leyes antisemitas en Alemania o en otros países centroeuropeos, o sobre la conducta de los judíos, con tonos similares a este titular: "Un judío, naturalmente, estafador" (Arriba España, 12-I-1938); etc. No se busquen noticias sobre roces entre la Iglesia católica y el III Reich, porque no se encuentran. Si acaso, lo contrario: todo era normal como en España, por eso - por ejemplo- el nuncio Orsenigo había celebrado una misa en Berlín, para celebrar el aniversario de la elección de Pío XI, ante algunas "altas personalidades" que representaban a Hitler y al Gobierno alemán (Arriba España, 13-II-1938, portada). 
necessario, con tutto il rigore, onde impedire a tempo il diffondersi di principi e dottrine contrastanti con gli insegnamenti della Chiesa e compromettenti la disciplina del Clero". ${ }^{108}$ Por supuesto, así lo haría el obispo de Pamplona:

"El señor Izurdiaga me he prometido cumplir fielmente mi orden y vivir alejado de toda actuación y representación política. Creo en la sinceridad de su promesa; pero no dejo de temer, por la debilidad de su carácter y el deseo de figurar, ciertas pequeñas incursiones en el terreno político, que le está vedado. Estaré al tanto para que así no sea". ${ }^{109}$

La formación del primer Gobierno de Franco, el 30 de enero de 1938, tranquilizó a ambos eclesiásticos respecto del futuro de Yzurdiaga. El martes 1 de febrero, Arriba España facilitó las biografías de los nuevos ministros. La de Ramón Serrano Suñer era particularmente elogiosa: "es hombre de carácter independiente y firme", se decía. Para que nadie pensase que actuaba por libre, su vínculo con las fuentes de la nueva legitimidad no ofrecía dudas: "comprendiendo la necesidad de una acción de tipo militar que atajase la revolución comunista, mantuvo estrecho contacto con el general Franco y con José Antonio Primo de Rivera". ${ }^{110}$ El diario percibió que Serrano era la figura estelar del momento y comenzó a prestarle una atención reservada a los Héroes. Como Franco, Serrano se sumaba, en vida, al panteón mitológico de Yzurdiaga.

Antoniutti tuvo motivos para el optimismo cuando el 8 de febrero envió un informe a la Secretaría de Estado. Se acababa de entrevistar con Serrano Suñer, y las noticias eran inmejorables. La primera era que la encíclica Mit brennender Sorge podía difundirse sin trabas, después de un año de bloquear los nacionales su texto en las publicaciones católicas, que es donde se iba a publicar ahora. ${ }^{111}$ La segunda noticia afectaba de pleno al cura azul. Serrano pasó a controlar la Delegación Nacional de Prensa y Propaganda antes dependiente de un Yzurdiaga juzgado por Antoniutti "di principi dottrinali poco sicuri e d'idee superficiali e strane". Además, el ministro quería "dare una nuova orientazione alla stampa della Falange, evitando false e perniciose influenze straniere". Para conseguirlo, le detalló tres medidas: de acuerdo con la autoridad eclesiástica, "due bravi sacerdoti" Delegación Nacional de Prensa para "vigilare e controllare le pubblicazioni e gli articoli di carattere religioso ed ecclesiastico"; estaba dispuesto Serrano a prohibir "le pubblicazioni tendenziose del 'Angriff'”, periódico berlinés fundado en 1927 por Goebbels; e, incluso, algún periódico había empezado ya "a fare la critica, sia pure in un modo discreto, delle dottrine e teorie naziste". ${ }^{113}$ Todo aquello era muy alentador, aunque Antoniutti acabó su informe prometiendo seguir la evolución de los acontecimientos.

Ese Serrano, que ya era uno de los iconos de Yzurdiaga y de su periódico, pasó a ser el nuevo Delegado Nacional de Prensa y Propaganda de FET y de las JONS. ${ }^{114}$ Esta Delegación de Falange se fusionaba con la otra Delegación del Estado en la persona y en los hombres de Serrano. Olaechea podía

${ }^{108}$ ADP, GD, Antoniutti a Olaechea, 18-I-1938; y AG 9, 119-120.

109 ADP, GD, Olaechea a Antoniutti, 23-I-1938.

${ }_{110}^{11}$ Arriba España, 1-II-1938, portada.

${ }^{111}$ Cfr. Martínez Sánchez, S. 2011: 8-11.

${ }^{112}$ Finalmente, fue nombrado Juan Tusquets, sobre cuya personalidad y actividad durante la guerra civil puede verse Domínguez Arribas, J. 2009: 241-290. Pero su designación fue, de nuevo, decidida unilateralmente, esta vez por Serrano (cfr. AG 9: Gomá a Tusquets, 24 febrero 1938, 374).

${ }^{113}$ El despacho, 8-II-1938, en ASV, AES, Spagna, fasc. 322, fol. 39 y fasc. 339 fol. 15; ASV, NM, nº 973. fasc. 4 , fols. 365-366.

${ }^{114}$ Arriba España, 10-II-1938, portada. Cfr. Domínguez Arribas, J. 2009: 167-172. 
quedarse tranquilo: se oficializaba la sucesión en ese puesto, sin que, por otra parte, se dijese una sola palabra sobre la dimisión o cese de Yzurdiaga.

Liberado de las enojosas aunque atractivas cargas oficiales de censura y propaganda, Yzurdiaga puso en marcha una sección en su periódico, los domingos, sobre temas de doctrina católica. Esa sección, llamada "Christvs", se inspiró en la hoja volandera titulada "Catolicismo", que se publicó antes de la guerra con el patrocinio del Diario de Navarra. ${ }^{115}$ La vigilancia de Olaechea incluía conocer y aprobar la iniciativa, que le serviría para poder decir en el Vaticano algo positivo del sacerdote, al viajar por aquellas fechas a Roma en visita ad limina. ${ }^{116}$

La ausencia del obispo coincidió con la reunión del Consejo Nacional de Falange, el 9 de marzo de 1938. Aunque en diciembre había presentado a Franco su dimisión como consejero, ahora fue invitado a ir, pues Franco no aceptó ni la decisión de Olaechea ni la renuncia del sacerdote a ese puesto. Los días que precedieron a la reunión fueron bastante tensos, si no para Yzurdiaga sí para el vicario de la diócesis, Juan José Santander, que le prohibió asistir. ${ }^{117}$ Sin embargo, Yzurdiaga viajó a Burgos y, camino de la capital castellana, escribió a los consejeros para justificar su ausencia del próximo Consejo:

"[...] para que no sea mal interpretada, o [vista] como una deserción de esta noble trinchera de trabajo y de servicio a España, en horas de responsabilidad y de guerra, pensando que esta obediencia pronta, sincera y gustosa a mi Jerarquía es también servicio, en su ejemplo, para los españoles de la Patria Nueva". 118

Ya que él no iba a estar, les recomendaba dar un sentido cristiano al Fuero del Trabajo que iban a aprobar en el Consejo. Su intención era entregar a los consejeros la carta en mano, pero no asistir a la reunión. Pero, según supo el vicario de Pamplona, Yzurdiaga sí que asistió. Santander lo contó indignado a Antoniutti y a Gomá, al que le dijo que aquello "me pareció una burla, un desprecio de la autoridad episcopal que le había prohibido actuar en esa forma". ${ }^{119}$ El Vicario también indicó a Yzurdiaga que le suspendía sus licencias ministeriales por no apartarse de la política. Pero éste:

“[...] alega ahora que no cree le alcance la suspensión, porque el Sr. Obispo le amenazó con ella 'si no presentaba la dimisión de sus cargos', y eso ya lo tiene hecho desde Diciembre, pretendiendo así, con ese apego literario al valor de las palabras, dar una interpretación absurda e ineficaz al precepto que ellas envuelven". ${ }^{120}$

Tras regresar Olaechea de Roma, Yzurdiaga le explicaría en su descargo que asistió para luchar en el Consejo porque el texto del Fuero del Trabajo tuviese un contenido católico, como lo interpretó el

115 Arriba España, 27-II-1938, p. 3.

${ }^{116}$ El obispo estuvo fuera desde el 24 de febrero (BOEOP, 1-III-1938, p. 91; y Arriba España, 2-III-1938, portada). La fecha de vuelta no está en el boletín eclesiástico ni en la prensa. Pero fue su Vicario Juan José Santander quien acudió el 9 y 10 de marzo a la bendición de las nuevas rotativas de El Pensamiento Navarro y al discurso del ministro de Justicia, Rodezno, en el Teatro Gayarre, en la fiesta de los mártires de la Tradición: en esas fechas aún no estaba de vuelta Olaechea, pues.

117 ADP, GD, vicario general a Antoniutti, 12-III-1938.

${ }_{118}$ ADP, GD, Yzurdiaga a los consejeros nacionales, 6-III-1938.

119 ADP, GD, Vicario a Gomá, 12-III-1938.

${ }^{120}$ ADP, GD, Vicario a Gomá, 12-III-1938. 
ufano Arriba España. ${ }^{121}$ La ausencia de fuentes sobre esa entrevista impide precisar el alcance de la reprimenda de Olaechea al sacerdote. Pero es significativo que no hubiese una nueva protesta del obispo a Franco sobre "los corolarios e inherencias": esto es, sobre que el cura siguiese siendo Consejero Nacional. Ni tampoco existen quejas del obispo al Arriba España ante noticias que presentaban al cura azul como Consejero Nacional. ${ }^{122}$ Que Olaechea le dio por cesado en el cargo es claro. Que no quiso insistir a Franco, también. Y también que exigió al sacerdote que no participara a las reuniones del Consejo. ${ }^{123}$

El sacerdote se concentró en Jerarquía ${ }^{124}$ y en Arriba España, donde había que orientar las muchas noticias de aquella primavera de 1938. Estaba el Anschluss de Austria, con toda una complaciente información al respecto: la pastoral de aceptación de los obispos austriacos; la llamada a Roma y retractación del cardenal primado, el cardenal Theodor Innitzer; el referéndum en Austria que aprobó la anexión; el entusiasmo de Hitler en Viena; la oración de los católicos vieneses por el Führer, etc. ${ }^{125}$ Y también había mucha información de interés en España: los discursos de Serrano Suñer; el avance hasta el Mediterráneo que partió la zona republicana en dos; o la promulgación de la ley de prensa, que elevaba al periodista "a esta tarea augusta de apostolado: informar al pueblo, dirigirle y adoctrinarle en la grandeza del pensamiento español", y que hacía de la Prensa "un acorde gozoso y fausto de servicio, de apostolado, de sacerdocio". ${ }^{126}$

La prensa era un sacerdocio y aquel sacerdote un periodista demasiado independiente para el gusto de su prelado. Hacía Yzurdiaga gala de una libertad que la reciente ley prohibía a su gremio: parecía emancipado de la ley eclesiástica que prohibía a los clérigos dirigir periódicos, tema que Olaechea había tocado un año antes, el 8 de mayo de 1937. El asunto había quedado en el limbo, mientras el obispo, calmadamente, peleaba para que renunciara a sus cargos políticos. De todos modos, Olaechea parecía ser el último en enterarse de que el sacerdote era director y alma de Arriba España, desde sus comienzos. En realidad, Yzurdiaga le había dicho que era sólo un redactor y el obispo le había creído.

No fue casual que actuase en ese asunto ahora, al regresar de su visita ad limina en Roma, donde quizá recibió instrucciones para clarificar la cuestión. En cualquier caso, antes de exigir su renuncia esperó a tener alguna prueba de que Yzurdiaga dirigía el diario. Y esto ocurrió el 5 de abril de $1938 .{ }^{127}$

${ }^{121}$ El editorial en portada del 12 marzo de 1938, titulado "Valores religiosos en el Fuero del Trabajo", insistía en que por vez primera "se han tomado normas y conceptos de las Encíclicas y de los más sanos postulados que tienden a construir con firmeza las rutas del Imperio. El Fuero del Trabajo es esencialmente católico, y es fruto de una recta meditación que valora y que exalta las virtudes de artesanía como herencia de nuestros gremios seculares".

${ }^{122}$ Cfr. Arriba España, 23 y 25-VI-1938, contraportadas; 15-XI-1938, p. 3; 1-I-1939, portada; etc.

${ }^{123}$ Pero, como en público el cargo se unía a su persona, pienso que el obispo y el sacerdote llegaron a un acuerdo o hubo un pacto tácito entre ellos: conservaba su puesto nominal de consejero (esto no dependía de Olaechea), pero no debía asistir a los consejos, algo que Olaechea sí podía ordenarle, prohibiéndole salir de la diócesis con tal finalidad. De hecho, así se lo volvió a prohibir en junio de 1939 (cfr. Andrés-Gallego, J. 1997: 57).

${ }^{124}$ En marzo de 1938 salió el número 3 de la pomposamente llamada "revista del Imperio, de la Sabiduría, de los Oficios" (cfr. Arriba España, 17-III-1938, contraportada, índice del número; y 24-III-1938, contraportada).

125 Por ejemplo, Arriba España, 16-III-1938, portada; 30-III-1938, contraportada; 7-IV-1938, contraportada; 10-IV-1938, portada y p. 3; 22-IV-1938, p. 3; etc.

${ }_{126}$ Arriba España, 27-IV-1938, editorial "Libertad y milicia de prensa", portada.

127 "He visto dos disposiciones firmadas por V. como "Director de Arriba España". Yo estaba en la creencia que V. no lo era. Redactor, sí; tiene V. mi licencia para ello y mi felicitación por la interesante página 
El obispo se adelantaba por poco a los inconvenientes de la nueva ley de Prensa, que convertía a los directores de periódicos en funcionarios al servicio del Estado, nombrados por el ministro del Interior. En el caso de don Fermín, Olaechea cortó la posibilidad de un nuevo pugilato con ese ministerio, donde trabajaban los camaradas Serrano Súñer, Laín Entralgo o Ridruejo, viejos conocidos del sacerdote.

El obispo, que había cerrado la plataforma política del sacerdote, comenzó a emitir señales que indicaban su interés en restringir también la esfera periodística de Yzurdiaga. Aparentemente, para evitar que el sacerdote se viese envuelto en polémicas, como las críticas contra la Asociación de la Prensa de Pamplona, aparecidas en Arriba España y en La Hoja de los Lunes. El 10 de mayo de 1938, Olaechea le impuso “que no escriba V. en 'Lunes', ni le preste apoyo ni asesoramiento de ninguna clase, hasta que desaparecida toda molestia, obtenga mi licencia por escrito". ${ }^{128}$ El sacerdote le reconoció al obispo que el 2 de mayo, tras leer un artículo "injurioso" en la Hoja contra los hombres de Arriba España, llamó a Serrano Suñer, explicándole que ése era el último ataque de una serie que duraba ya cuatro meses. Resultado: Javier Arvizu fue destituido como director de la Hoja y en su lugar Serrano puso a Ángel María Pascual, que brindó las columnas del periódico a Yzurdiaga, escribiendo éste el día anterior (9 de mayo) un artículo donde se despachaba a gusto contra Arvizu y sus manejos. ${ }^{129}$

Que ese mismo día el obispo le exigiese también cesar como director de la revista Jerarquía indica una decisión de acotar el protagonismo del sacerdote a las cuestiones estrictamente doctrinales de la sección religiosa "Christvs". Olaechea encontró un pretexto ideal en un episodio que llegó entonces a sus oídos.

Yzurdiaga viajaba con frecuencia a Burgos. Allí estaban sus contactos políticos, muy particularmente Serrano Súñer, allí residía Franco, allí se concentraba el poder, que atraía como un imán a don Fermín. Tenía audiencia con el Generalísimo el 4 de mayo, en Burgos. Estaba entonces de visita en la ciudad Charles Maurras, fundador de Action Française. Maurras, excomulgado a finales de 1926 por su desobediencia al magisterio católico, era una destacada personalidad francesa que apoyaba la causa franquista. Por eso, aquel miércoles 4 de mayo hubo en su honor un banquete, en el hotel Condestable, el mismo donde solía hospedarse Yzurdiaga. Acabado el almuerzo, Maurras se acercó a

religiosa. Director no puede serlo; y si como yo supongo tiene el cargo en interinidad, aún así tengo que imponerle y le impongo el que lo renuncie, sin pérdida de tiempo. A ningún sacerdote consentiré el que dirija un Diario en esta Diócesis. Ya puede pensar V. qué montón de enojosidades [sic] caen sobre un Director de un Diario. Algunas caen sobre V. en ese reajuste de personal, aunque se haga con toda justicia. Tenga lo dicho por una orden clara y terminante. Ruegue por mí, que no le olvido en mis oraciones ni en mi afecto" (ADP, GD, Olaechea a Yzurdiaga, 5-IV-1938). Según García Serrano, R. 1983: 178, Yzurdiaga había sido nombrado director por Serrano al formarse el primer Gobierno de Franco.

${ }_{128}$ ADP, GD, Olaechea a Yzurdiaga, 10-V-1938.

129 “[...] y entonces yo llamé por teléfono al Sr. Ministro del Interior y escuetamente le di lectura de todo el artículo que acompaña a este escrito. Si en un asunto, sentenciado ya, esta intervención mía pudo ser el acicate para resolverlo rápidamente, estoy de ello orgulloso y tranquilo porque no he hecho otra cosa que el vindicar cristianamente la justicia y salir por el buen nombre de unos periodistas que no hacen otra cosa, con su labor diaria, que exaltar los derechos de Cristo, de la Iglesia y de la Patria. Clara es mi actuación: y no puedo tolerar que a esto llamen "manejos míos". Pero hay más. Me dice V.E. que han sido "seis ejemplares caballeros cristianos' los que han ido a protestar de mi actuación". Pues les dice que deberían no haber protestado ante usted, sino ante el ministerio que removió al director Arvizu. Y que al acudir a usted han intentado vengarse de mí: no han intentado otra cosa que ponerme en entredicho y conseguir a través de V.E. una mortificación, un disgusto, una pena de cualquier orden que esta fuera, con tal de tomarse la venganza y la justicia por su mano" (ADP, GD, Yzurdiaga a Olaechea, sin fecha). 
saludarle. Yzurdiaga se levantó pero, las manos a la espalda, no le saludo ni le habló, pues su presencia en aquel acto había sido una suma de confusiones, que el cura sentía profundamente. Una última circunstancia completaba aquel episodio. Era su artículo "Sentir con la Iglesia" en la sección "Christvs", del domingo 8 de mayo. Yzurdiaga, según contaba luego a su obispo, quería "públicamente y rubricado [hacer] consta[r] mi afecto, mi fidelidad hasta la muerte, a nuestra madre la Iglesia de Roma". ${ }^{130}$

A don Marcelino, sin embargo, le había llegado una versión del asunto más simple y escandalizante, algo así como: ¡Yzurdiaga, el conocido sacerdote, almuerza con Maurras, un excomulgado! Y el 10 de mayo le escribió en estos términos:

"Muy querido Don Fermín:

"Otro asunto desagradable, y muy mucho, para mí.

"Su presencia en el Banquete, ofrecido en honor de Maurras, ha causado escándalo en los católicos bien instruidos; como causaría pena al Santo Padre, si llegara a saber que un sacerdote ha rendido ese honor a un excomulgado.

"Si a esa mesa le forzó el cargo de Director de Jerarquía, como me dicen, la renuncia se impone, como penitencia necesaria; si le llevó a ella una ligereza, una debilidad o una ignorancia, disponga sus cosas para acudir a primera tanda de Ejercicios Espirituales para sacerdotes, en la casa de Burlada.

"Venga a verme; ruegue por su afmo. amigo". ${ }^{131}$

Efectivamente, se vieron el 12 de mayo. En aquella entrevista, Olaechea dio por buenas sus explicaciones sobre que no estaba allí ni invitado, ni representando a Jerarquía. Así que dejó estar el asunto. ${ }^{132}$ Posiblemente, también aceptase las protestas del cura sobre el carácter católico de sus iniciativas:

" $7^{\circ}$. Pido que enfrente de este hecho de mi asistencia a la comida a Maurras por lo que en ello hubiera de escándalo, se ponga toda la labor pública, extensa y eficaz, que durante dos años he hecho con la palabra, con la pluma y con mi intervención cerca de las Jerarquías del Estado y de la Falange para asegurar a este movimiento una Fe Católica firme, que no he dejado de publicar nunca". ${ }^{133}$

El sacerdote había logrado convencerle de su inocencia, sabiendo que se jugaba perder su plataforma cultural más influyente, pues el alcance de Arriba España era más regional, entre las minorías intelectuales y políticas de la España franquista. Yzurdiaga no olvidaba que Franco, Serrano Súñer o la Falange no eran el cordón umbilical que daban vida o nutrían sus iniciativas. Más bien, era su obispo el factor que aseguraba la supervivencia de su tarea. ${ }^{134}$

${ }^{130}$ Todo lo anterior se lo contó de palabra a Olaechea más tarde, el 12 de mayo. El obispo quería que escribiera el relato de los hechos "ya que según su expresión [de Olaechea], es muy necesario que quede constancia de todo esto para la Historia”. Así lo hizo don Fermín el día siguiente, 13, con una prolija carta, de donde extraigo la cita (ADP, GD, Yzurdiaga a Olaechea, 13-V-1938).

${ }^{131}$ ADP, GD, Olaechea a Yzurdiaga, 10-V-1938.

132 Olaechea envió a Antoniutti la carta de Yzurdiaga, añadiendo que "Creo en su sinceridad y por tanto atribuyo a sorpresa su presencia en el referido banquete” (ADP, GD, Olaechea a Antoniutti, 17-V-1938).

133 ADP, GD, Yzurdiaga a Olaechea, 13-V-1938.

${ }^{134}$ García Serrano, R. 1983: 178, recuerda que "una llamada del palacio episcopal al periódico conmovía a don Fermín, y acudía a la convocatoria con respeto, prisa y a veces cierta inquietud". 
En el aprisco de la Falange, su labor la concebía Yzurdiaga, y el obispo debía de estar también de acuerdo, como un apostolado, una catequesis evangelizadora. Discrepaban en las actuaciones apasionadas e incómodas, agresivas e intemperantes, impredecibles incluso. Pero don Marcelino no le tenía por heterodoxo ni insumiso. En el mundo eclesiástico, Yzurdiaga podía respirar tranquilo si su obispo le respaldaba.

Al suponer precaria su posición ante los rumores que circulaban sobre su asistencia al banquete, el sacerdote escribió un artículo, "Sentir con la Iglesia", el 8 de mayo. Era su glosa a unas instrucciones dirigidas a los centros educativos católicos por la Congregación de Seminarios y Universidades, presidida por el mismo Pío XI. Esas instrucciones se conocieron en la portada de L'Osservatore Romano el 3 de mayo de 1938, durante el viaje de Hitler a Roma. ${ }^{135} \mathrm{Su}$ finalidad era alertar a los académicos y centros católicos de educación superior ante algunas "detestables" propuestas sobre la idolatría de la raza, del Estado y del panteísmo neopagano nazi. ${ }^{136}$ Ese documento no se difundió en la prensa de la España nacional. Yzurdiaga sí lo hizo, también en defensa propia. Por eso, le faltó tiempo para enviarlo a Ildebrando Antoniutti, quien cambió su juicio sobre las "extrañas ideas" de Yzurdiaga, al interpretar que las siguientes líneas de su artículo distanciaban al cura del nazismo:

"Parece un delirio de locura inventar la 'religión de la sangre', 'el culto de la raza', la 'pedagogía de la selección de los pueblos'. Y, sin embargo, en los libros de algunas Universidades -fuera de España, desde luego- se propaga el error con sutiles ropajes de aparato científico.

"[...]

"Habló Roma: con la autoridad permanente de su misión veladora e intérprete del depósito de la Revelación. Grande y augusta Voz". ${ }^{137}$

Antoniutti informaba en su despacho al Vaticano que Yzurdiaga había cambiado su "actitud filonazista" gracias a la intervención del obispo. La cosa no había sido exactamente así, como hemos visto. La feliz noticia coincidía con otras también positivas, que revelaban un cambio de ambiente hacia el nazismo en las alturas de la España nacional, según Antoniutti. Franco, por ejemplo, al comentarle a Antoniutti la visita de Hitler a Roma y la ausencia de Pío XI, que se marchó a Castel Gandolfo para no coincidir con él, le había dicho " 'che l'attitudine di Hitler verso i cattolici 'es una verdadera locura". Y Pilar Primo de Rivera, tras su reciente viaje a Alemania, había declarado que "stando in Spagna non poteva avere un'idea dell'orientazione anticristiana che si dà alla gioventù femminile nazista tedesca". ${ }^{138}$ El cardenal Pacelli dio acuse de recibo a Antoniutti ${ }^{139}$ cuando ya se conocía públicamente que la España de Franco y el Vaticano intercambiaban embajadores, Gaetano Cigognani y José Yanguas Messía. ${ }^{140}$

Arriba España interpretó polémicamente la normalización diplomática: por fin, Roma reconocía "la verdad de la guerra [como Cruzada] y el católico derecho del Caudillo" a iniciarla y ganarla, y desautorizaba así a los “"sturzistas” del mundo que han denostado nuestro movimiento tachándole de

${ }^{135}$ G. Passelecq, B. Suchecky. 1997. The Hidden Encyclical of Pius XI: 113-115 New York: Harcourt Brace.

${ }^{136}$ Cfr. BoEOP, 15-XI-1938, pp. 456-458.

${ }^{137}$ Arriba España, 8-V-1938, contraportada; enviado a Pacelli 16-V-1938: ASV, AES, Spagna, fasc. 322, fol. 43.

${ }^{138}$ ASV, AES, Spagna, fasc. 322, fols. 41-42 y fasc. 339, fol. 16: Despacho a Pacelli, 16-V-1938 (cfr. Primo de Rivera, P. 1983. Recuerdos de una vida: 209-210 Madrid: Dyrsa).

${ }^{139}$ ASV, AES, Spagna, fasc. 339, fol. 17: Pacelli a Antoniutti, 30-V-1938.

${ }^{140}$ Cfr. Arriba España, 17-V-1938, p. 2. 
racista, de inhumano, de ilegítimo, de anticristiano y de antisocial". ${ }^{141}$ No había peores enemigos que los católicos que ni apoyaban a Franco ni confiaban en un Estado donde todo lo fascista era católico y todo lo católico debía ser fascista. La idea, muy del gusto de Yzurdiaga, era un argumento insistente de su diario. Y, desde luego, se podía afilar más.

El editorial del 20 de mayo de 1938 se titulaba “¿Qué hay detrás?”. Acusaba de hacer el juego al enemigo a ciertos "elementos enquistados" en la Acción Católica. Si "quien tenga la oportuna autoridad no desenmascara esta intromisión de elementos extraños en la Acción Católica", el diario auguraba "grandes y tristes perturbaciones", pues el fascismo, por reacción, se haría "apóstata y anticatólico". Por si esta predicción fuera insuficiente, el editorialista contrastaba toscamente el ardor fascista de los obispos y sacerdotes italianos, que eran "fascistas de corazón y de pensamiento", con la frialdad que tenían en España hacia el fascismo esos misteriosos elementos enquistados. ${ }^{142}$

Al obispo de Pamplona le faltó tiempo para reaccionar. Ese mismo día envió a "Ángel María Pascual, director de Arriba España" una larga carta para publicar y así "deshacer la confusión y el ambiente creado" por el editorial. ${ }^{143}$ El obispo negaba la mayor sobre el Estado: "no es posible negar que un Estado Fascista puede no ser católico; y puede no ser católico, a pesar de jactarse de ello". Objetaba las "insinuaciones injustas" contra la Acción Católica, pues no había en ella "ninguna traza de política". Y recordaba que "El sacerdote hace toda la Patria que debe y toda la política que debe, siendo un sacerdote ejemplar y nada más que eso. La actuación política, por alta que ésta sea, es ajena a su ministerio". ${ }^{144}$

Las ideas de aquella carta se alojaron en el diario como seres extraños, pero Pascual e Yzurdiaga evitaron polemizar con el obispo. Por supuesto, la carta no varió ni un ápice la línea editorial de Arriba España, que seguía en sus trece exigiendo desenmascarar "al enemigo de dentro", porque entonces más que nunca, cuando la guerra podía acabar en breve, había que "limpiar el camino de parásitos que lleven en su zalema pegajosa y rastrera el puñal que ha de clavarse en la carne de la Falange". ${ }^{145}$

Para Yzurdiaga, lo más sensato para no perjudicar su inestable posición era mantener la línea argumental de su artículo "Sentir con la Iglesia", esquivando topetazos que le perjudicarían a él más que a nadie. Por eso, andaba con cuidado, centrado en la sección religiosa "Christvs", en marcha desde febrero de 1938. Pero, de vez en cuando, embestía incapaz de contenerse si alguien cuestionaba la catolicidad de sus iniciativas. Tuvo su estilo altisonante un artículo sin firma contra Blas Goñi, un canónigo de la catedral de Pamplona que era asiduo colaborador de El Pensamiento Navarro. Como Goñi había dudado de que Arriba España fuese un diario católico, Yzurdiaga pedía que "nuestro delegado nacional, camarada Serrano Suñer" interviniese contra ese tipo de actuaciones indeseables. ${ }^{146}$

${ }_{141}$ Arriba España, 18-V-1938, portada.

${ }^{142}$ Arriba España, 20-V-1938, portada.

143 ADP, GD, Olaechea a Pascual, 20-V-1938.

${ }^{144}$ Arriba España, 21-V-1938, contraportada. El obispo le agradeció a Pascual la publicación de su carta: "Acabo de leer mi carta abierta en ese querido Diario. Muy bien; y como lo que son: buenos hijos de la Iglesia. Agradecido; rogando al Señor les bendiga copiosamente" (ADP, GD, Olaechea a Pascual, 21-V-1938). Es bien insólita esta carta, prácticamente la única vez que pudo conocerse públicamente algo sobre estas tensiones ocurridas en las alturas político-religiosas. En este sentido, Alfonso Botti ha señalado el carácter privado del enfrentamiento en torno a Yzurdiaga: cfr. Botti, A. 2011. "Il clero nella guerra spagnola del 1936-1939”, en A. Botti (ed), Clero e guerra spagnole in età contemporanea (1808-1939): 378. Soveria Mannelli: Rubbettino Editore.

${ }^{145}$ Arriba España, 19-VI-1938, editorial "Estad vigilantes", portada.

146 Arriba España, 30-VI-1938, portada. Serrano intervino, pero para una cuestión de más fuste, como la 
A la vista de lo que le había pasado a Arvizu, esa súplica podía tener consecuencias desagradables para el diario en el que escribía el canónigo Goñi.

Fermín Yzurdiaga sabía que "Christvs" no era el lugar ideal para insertar artículos netamente políticos, que tanto le atraían. Así que para reafirmar algunas cuestiones sobre la naturaleza de Falange, inició en su diario en agosto del 38 la sección titulada "Con las cinco flechas en el yugo", que firmaba él con su nombre y dos apellidos. El segundo de aquellos artículos, "Salida al encuentro. Falange, Raza y Racismo", apareció en portada el 14 de agosto, domingo. El sacerdote confrontaba la doctrina falangista y el dogma católico sobre el "problema judío", para concluir que Falange "no es, ni puede ser, racista, si antes no traiciona su Doctrina y vacía de sentido su concepción de hombre, de Patria, de Imperio". La afirmación era muy rotunda y contrastaba con el antijudaísmo presente en el diario desde el primer entrefilete del 1 de agosto de $1936 .{ }^{147}$

No fue este contraste el que sorprendió al nuncio del Vaticano, monseñor Gaetano Cicognani, a finales de agosto. El diplomático, que informó a Roma sobre actividades de la Falange, se preguntaba hasta qué punto esa cita, que transcribía, era una expresión sincera o una táctica propagandística importada de Alemania para confundir a los católicos:

"Ciò nonostante la perplessità rimane, non perché non si creda alla sincerità di queste parole, ma perché si teme che fra i falangisti ve ne siano anche di quelli, i quali, a somiglianza dei nazional-socialisti tedeschi, fingono amore e riverenza al cattolicismo al solo scopo di combatterlo con maggior successo; e perché si sa che tra i falangisti vi è tutta una moltitudine di persone che sono entrate nel partito non per convinzioni di programma, ma per interesse personale". ${ }^{148}$

La desconfianza del diplomático hacia Yzurdiaga, al que dibujaba más como un falangista pronazi que como un genuino católico que militaba en Falange, no tiene porqué sorprender. Sus dudas, alimentadas por su experiencia como nuncio en Austria hasta el Anschluss, procedían de las alabanzas de Arriba España a la Alemania nazi, como reveló de nuevo la amplia cobertura a los "brillantes" e "históricos" discursos de los jerarcas nazis en el "magno" congreso nazi de Nuremberg, celebrado al poco de fechar Cicognani su informe. ${ }^{149}$ Pero, también, influían mucho en sus recelos las actuaciones de Yzurdiaga, que ya conocemos y que, sin duda, pesaban más que sus artículos de prensa.

concesión de una distinción para Yzurdiaga por sus servicios prestados. En el segundo aniversario de la guerra, Franco otorgó distintas condecoraciones a personalidades como Herman Goering ("Mariscal del Reich Alemán y Presidente del Consejo de Ministros de Prusia"), el conde Guido Viola di Campaldo (embajador de Italia en Burgos), el conde Galeazzo Ciano (ministro de Exteriores italiano), Pilar Primo de Rivera, Ildebrando Antoniutti ("Ex representante de la Santa Sede en España") o Yzurdiaga, que figuraba en el decreto como "Consejero Nacional" y que recibió la Placa de la Gran Orden Imperial de las Flechas Rojas (Arriba España, 19-VII-1938, portada)

${ }^{147}$ Quizá por eso, dos días después Arriba España aclaraba lo siguiente en el editorial "Cuatro escolios a un artículo sobre racismo": "porque no somos racistas, porque no reconocemos los valores de la sangre, sino los valores del espíritu, somos esencialmente, fundamentalmente, enemigos de los judíos". Falta un estudio sobre el antisemitismo de Arriba España, aunque hay bastantes referencias a este diario en Domínguez Arribas, J. 2009: 193-195.

${ }_{148}$ ASV, AES, Spagna, fasc. 336, fol. 47: despacho a Pacelli, 28-VIII-1938.

${ }^{149} \mathrm{Cfr}$. el diario entre el 7 y 14 de septiembre de 1938. 


\section{EL OCASO}

Concluían los días en que la firma de Yzurdiaga se asomaba a su propio diario. En septiembre, firmó dos artículos sobre la catolicidad de la Falange. ${ }^{150}$ Fueron otros dos en octubre: una loa a los caídos, en el aniversario de la muerte de Primo de Rivera, titulada "Lección y profecía de los caídos", y una "Meditación sobre la realeza de Cristo en el alba de una nueva edad" al día siguiente. ${ }^{151}$ Fue su último artículo en la sección "Christvs".

Los siguientes domingos, 6 y 13 de noviembre de 1938, toda esa sección fue para publicar un tratado sobre el Purgatorio, de santa Catalina de Génova. Otras firmas ocuparon la sección los dos siguientes domingos. Y el sábado 3 de diciembre el diario informó que un extraordinario sobre san Francisco Javier estaba previsto para el domingo 4. Pero ni aquello se publicó, ni tampoco había ya rastro alguno de "Christvs", sección que se esfumó sin ninguna explicación sobre su cierre ni sobre su fundador. ¿Qué había pasado?

Pasó que Mons. Olaechea creyó que el sacerdote le engañaba y le retiró las licencias para escribir. Y eso, de un día para otro. La cosa comenzó con una llamada de teléfono de Yzurdiaga a Miguel Uranga, el 8 de noviembre. La telefonista escuchó que el cura hablaba de iniciar una campaña de prensa sobre unos monjes que abandonaban un monasterio. Como esa campaña, decía al parecer Yzurdiaga, la haría "aun cuando le pese al Cardenal Gomá, publicando unos documentos que, pese a quien pese -repite- iban a dar mucho que hablar en el extranjero", quien escuchaba atendió mejor y tomó nota de los otros temas de ésa y de otra conversación de Yzurdiaga con Ángel María Pascual, de la que podía concluirse que el sacerdote dirigía el diario Arriba España. Al recibir un resumen de estas llamadas, el gobernador militar se apresuró ese mismo día 8 a hablar con Gomá. Y éste, como el gobernador prefería no intervenir y que todo se hiciese por el conducto reglamentario, le pasó a Olaechea esa información el día 11. ${ }^{152}$ El primado esperaba, eso sí, que Olaechea tomase la "disposiciones que juzgue oportunas".

Y vaya que si las tomó. El mismo 11, Olaechea escribió la siguiente carta al sacerdoteperiodista:

"Muy apreciado Don Fermín:

"Tengo con dolor que decirle, que tengo pruebas de ser V. director de un Diario; que así consta en Burgos y como tal cobra $\mathrm{V}$. su nómina.

"V. sabe perfectamente que no puede serlo sin mi permiso; es más, sabe V. que ese permiso yo no sólo no se lo he dado, sino que una vez que sospeché que ostentaba $V$. ese cargo le llamé para que me explicara su conducta y $\mathrm{V}$. me aseguró que no era tal director.

"En virtud de ello, yo con esta carta le prohíbo sub poena suspensionis ipso facto incurrenda el ser director, el figurar como tal, o el cobrar la nómina de idem. Es más, decididamente creo que debe V. alejarse del periodismo político ya como escritor, ya como inspirador; y por tanto bajo la misma gravedad y pena le prohíbo el ir a redacción de Diarios, y el escribir en ellos con nombre propio, seudónimo y ajeno, a no ser de cosas religiosas, y éstas sometidas todas de antemano a mi censura.

"Su mayor bien lo reclama; y en él me inspiro. Afmo. amigo."153

${ }^{150}$ Arriba España, 11-IX-1938, p. 6; 18-IX-1938, p. 5.

${ }^{151}$ Arriba España, 29-X-1938, portada; y 30-X-1938, p. 6.

${ }^{152}$ ADP, GD, "Nota entregada por el Excmo. Gobernador militar al primado el 8 de noviembre" y carta de Gomá a Olaechea, 11-XI-1938. Este documento no se encuentra en el volumen correspondiente del AG.

${ }^{153}$ ADP, GD, borrador a máquina de Olaechea a Yzurdiaga, 11-XI-1938. 
Olaechea escribió al gobernador civil de Navarra, Francisco de la Rocha, el 15 de noviembre. Le explicaba que tenía pruebas de ser Yzurdiaga el director del Arriba España; que tenía su "permiso para escribir en los Diarios sólo de asuntos religiosos pero de ninguna manera de otros"; que le prohibía toda actividad periodística; y que comunicase a su superioridad que el puesto de director del diario estaba vacante. ${ }^{154}$

Para Yzurdiaga, la cosa venía por una "calumnia, tramada burdamente contra mí". ${ }^{155}$ Envió al obispo un acta notarial que acreditaba que en sus conversaciones telefónicas del 8 de noviembre tocaron otros temas (¿?). El sacerdote veía "desmoronarse una obra ejemplar que creé, con indecibles dificultades y hasta lucha de los enemigos de la Religión y de la Iglesia", porque la prohibición de Olaechea tenía efectos fulminantes, como bien deducía don Fermín:

“[...] No es posible, dentro de las características de los periódicos, publicar una página semanal 'sin poder entrar en el periódico': disponer el original adecuado y justo, atender al montaje y ajuste, etc.

"Yo le ruego, con el mayor encarecimiento, si con todas esas razones puede modificar su decisión última, o por lo menos, cambiar y mitigar la suspensión. Públicamente hablé y escribí. Nadie podrá demostrarme haber rozado, siquiera, la ortodoxia católica y, sí, en toda mi obra se puede reconocer un fin claro y ardiente de apología". ${ }^{156}$

Pero el obispo se negó a dar su brazo a torcer, amparándose en que las decisiones de la junta de metropolitanos celebrada un año antes limitaban la actividad política de los sacerdotes. ${ }^{157}$ Así pues, un escueto "no puedo acceder a lo que pide"158 cerraba la actividad del sacerdote en Arriba España y condenaba a muerte a la revista Jerarquía, cuyo cuarto número, que llevó la escueta fecha de "1938", fue ya el último en editarse.

\section{CONCLUSIONES}

En el ascenso y ocaso de Yzurdiaga su personalidad influyó tanto como el cambio de panorama en julio de 1936. Su talento literario, su capacidad para liderar equipos, sus metas políticas, su militancia falangista, su carácter sacerdotal y su misma juventud le empujaban más consciente que casualmente a la arena pública: disfrutaba bajo los focos, en el centro del escenario. El inicio de la guerra le sorprendió siendo ya dueño de un patrimonio intelectual bien definido, que sólo necesitaba para plasmarse de plataformas de acción y de colaboradores. Para ello, su militancia falangista fue determinante, porque Arriba España, Jerarquía y la Delegación de Prensa y Propaganda de Fet y de las Jons eran poderosos reclamos para arrimarse a él, por convicción o por interés. En 1936 y 1937 , Fermín Yzurdiaga fue, sin ninguna duda, una estrella emergente en la España de Franco. Con un brillo, claro está, prestado y no propio.

${ }^{154}$ ADP, GD, Olaechea a De la Rocha, 15-XI-1938.

${ }^{155}$ ADP, GD, Yzurdiaga a Olaechea, 6-XII-1938.

${ }_{156}^{150}$ AD, GD, Yzurdiaga a Olaechea, 6-XII-1938.

${ }^{157}$ Cfr. Redondo, G. 1993. Historia de la Iglesia en España. tomo II. La guerra civil, 1936-1939: 379 Madrid: Rialp.

${ }^{158}$ ADP, GD, Olaechea a Yzurdiaga, 7-XII-1938. 
Cómo consiguió despuntar y por qué fracasó el sacerdote, son la misma pregunta o, si se quiere, dos cuestiones que ofrecen una respuesta común. Su identidad era mixta y compleja: mitad sacerdote, mitad falangista, o tan falangista como sacerdote. Emergió y cayó por ser la suma de esas mitades. Su ingenua aspiración de conciliar con la fe católica una ideología secular, embrionaria, poco sistemática y sometida a influencias extranjeras, chocó con los recelos de sus superiores eclesiásticos. De una parte, con la Santa Sede: no se olvide la clara posición doctrinal de Pío XI con la Mit brennender Sorge, en la primavera del 37. De otra, con Olaechea y, especialmente con Gomá, bastante convencido el arzobispo de Toledo, a partir del otoño de 1937, del influjo de ideas paganizantes provenientes del nazismo alemán en la Falange unificada por Franco y en el Estado que despuntaba en la zona sublevada.

Así pues, la conclusión se imponía: los obispos aspirarían a reforzar cuanto enfriase esas tendencias peligrosas dentro de Falange o de la incipiente estructura política franquista. ¿Por qué esto no ocurrió con Yzurdiaga, que proclamaba a los cuatro vientos que ése era su objetivo y que, además, ocupaba una posición ideal para influir políticamente? Porque el establishment eclesiástico creyó, sobre razones fundadas en la propia actividad del cura azul, que alguien como él dependiente por igual del poder político y del religioso, acabaría traicionando ese catolicismo que aspiraba a introducir en la vida de la Nueva España.

A los ojos de la jerarquía eclesiástica, Yzurdiaga y sus empresas producían más confusión entre los católicos españoles que los resultados inequívocos, tangibles, que podía recibir la Iglesia de su apoyo. Su apartamiento y marginación, al que contribuyó su carácter vehemente y polémico, se hizo así inevitable al consumir a finales de 1938 la paciencia episcopal de Marcelino Olaechea.

En definitiva, el caso Yzurdiaga fue algo más que un conflicto disciplinar entre un cura y su obispo, pues originó tensiones ideológicas y políticas en cuya gestión, como hemos visto, intervinieron las más altas personalidades político-religiosas de la España franquista: Franco, Serrano Súñer y el cardenal Gomá, además de Ildebrando Antoniutti, delegado de la Santa Sede y luego su encargado de negocios ante el Gobierno de Burgos.

Fue, sin duda, un choque de carácter privado, librado en la trastienda del poder, del que se tuvo escasa o ninguna información pública en la España sublevada. La discreción sobre los problemas que generaba Yzurdiaga es un dato de gran relieve. Evidencia la afinidad entre los prelados españoles y Franco, el común deseo de todos de ganar la guerra, pues formaban parte del mismo bando nacional. Pero la misma existencia de los conflictos que hemos analizado confirma la voluntad de aquellos eclesiásticos de marcar distancias y evitar confusiones con el sector falangista partidario de construir un proyecto totalitario de Estado. Y, a mi juicio, demuestra que la colaboración de la jerarquía de la Iglesia española en la "hoja de ruta" del régimen franquista en construcción tenía unas líneas rojas, de las que el caso Yzurdiaga fue un buen exponente.

\section{BIBLIOGRAFÍA}

Andrés-Gallego, J. 1997. ¿Fascismo o Estado católico? Ideología, religión y censura en la España de Franco 1937-1941: Madrid: Encuentro.

Andrés Gallego, J. 1997. "La muerte de Pelayos y el nacimiento de Flechas y Pelayos (1938)". Hispania Sacra 49: 87-113. 
Andrés-Gallego, J. y Pazos, A. 2004-2005. Archivo Gomá. Documentos de la Guerra Civil: Madrid: CSIC, vols. 6 a 8.

Anuario Eclesiástico 1923: Barcelona: Subirana.

Anuario Eclesiástico 1927: Barcelona: Subirana.

Berzal de la Rosa, E. 2001, "Marcelino Olaechea Loizaga”. XX Siglos 47: 83-85.

Botti, A. 2011. "Il clero nella guerra spagnola del 1936-1939", en A. Botti (ed), Clero e guerra spagnole in età contemporanea (1808-1939): 367-397. Soveria Mannelli: Rubbettino Editore.

Botti, A. 2010. "Santa Sede e influenza nazista nella Spagna durante la guerra civile nei documenti dell'Archivio Segreto Vaticano. Un ruolo anti-totalitario della Chiesa?", en A. Guasco, R. Perin (eds.), Pius XI: Keywords: 107-129. Zurigo-Berlino: Lit.

d'Almeida, F. 2008. El pecado de los dioses. La alta sociedad y el nazismo: Madrid: Santillana.

Domínguez Arribas, J. 2009. El enemigo judeo-masónico en la propaganda franquista (1936-1945): Madrid: Marcial Pons Historia.

Ferrer Muñoz, M. 1992. Elecciones y Partidos Políticos en Navarra durante la Segunda República: Pamplona: Gobierno de Navarra, Departamento de Educación y Cultura.

García Serrano, R. 1983. La gran esperanza. Nosotros, los falangistas: Barcelona: Planeta.

Guía Diocesana de Pamplona, 1937. Pamplona: Imprenta Diocesana.

Gutiérrez García, J. L. 2010. Historia de la Asociación Católica de Propagandistas. Ángel Herrera Oria. Segundo período (1923-1935): Madrid: CEU Ediciones.

Herrero Suárez, H. 2007. Un yugo para los flechas. Educación no formal y adoctrinamiento infantil en Flechas y Pelayos: Lleida: Milenio.

Jerarqvía. La revista negra de la Falange (1936-1938). Edición íntegra. 2011. Madrid: Ediciones Barbarroja.

Laín Entralgo, P. 1976. Descargo de conciencia (1930-1960): Barcelona: Barral.

Martínez Sánchez, S. 2011. "El episcopado español ante la encíclica Mit brennender Sorge, 19371938”, en Á. Barrio Alonso, J. de Hoyos Puente, R. Saavedra Arias (eds.), Nuevos horizontes del pasado. Culturas políticas, identidades y formas de representación, Santander: Ediciones de la Universidad de Cantabria, comunicación electrónica. http://www.ahistcon.org/docs/Santander/contenido/indice-mesa6.html

Martínez Sánchez, S. 2004. Los papeles perdidos del cardenal Segura, 1880-1957: Pamplona: Eunsa.

Moral Roncal, A. M. 2009. La cuestión religiosa en la Segunda República española. Iglesia y carlismo: Madrid: Biblioteca Nueva.

Ordovás, J.M. 1993. Historia de la Asociación Católica Nacional de Propagandistas. De la Dictadura a la Segunda República (1923-1936): Pamplona: Eunsa.

Passelecq, G., y Suchecky, B. 1997. The Hidden Encyclical of Pius XI: New York: Harcourt Brace.

Payne, Stanley G. 1986. Falange. Historia del fascismo español: Madrid: Sarpe.

Pazos, A. M. 1990. El clero navarro (1900-1936). Origen social, procedencia geográfica y formación sacerdotal: Pamplona: Eunsa.

Primo de Rivera, P. 1983. Recuerdos de una vida: Madrid: Dyrsa. 
Raguer, H. 1999. "La actuación de Monseñor Marcelino Olaechea durante la Guerra Civil", en X. Quinzá Lleó y J. J. Alemany (eds.), Ciudad de los hombres, ciudad de Dios. Homenaje a Alfonso Álvarez Bolado, sj: 451-459. Madrid: Universidad Pontificia de Comillas.

Redondo, G. 1993. Historia de la Iglesia en España. tomo II. La guerra civil, 1936-1939: Madrid: Rialp.

Ridruejo, D. 1977. Casi unas memorias: Barcelona: Planeta.

Roca, T. 1968. Historia de la Obra de los Tribunales Tutelares de Menores en España: Madrid: Consejo Superior de Protección de Menores.

Sanz-Orrio y Arraiza, E. 2009. Fermín Sanz-Orrio, luchador por la justicia social: Astorga: Akrón.

Saña, H. 1982. El franquismo sin mitos. Conversaciones con Serrano Suñer: Barcelona: Grijalbo.

Sesma, N. 2011. "De la elite intelectual a la aristocracia política. El discurso de la renovación ideológica y generacional en Gerarchia. Rassegba mensile della rivoluzione fascista y Jerarquía. La revista negra de la Falange", en Francisco Morente (ed.), España en la crisis europea de entreguerras. República, fascismo y guerra civil: 269-288. Madrid: Libros de la catarata.

Sinova, J. 2006. La censura de prensa durante el franquismo: Barcelona: Debolsillo.

Yzurdiaga, F. 1927. Poema de Navarra: Pamplona: Aramburu. 